FEDERAL RESERVE BANK OF SAN FRANCISCO

WORKING PAPER SERIES

\title{
LEARNING, ADAPTIVE EXPECTATIONS, AND TECHNOLOGY SHOCKS
}

\author{
Kevin X.D. Huang \\ Vanderbilt University \\ Zheng Liu \\ Federal Reserve Bank of San Francisco \\ and Emory University \\ Tao Zha \\ Federal Reserve Bank of Atlanta \\ and Emory University \\ September 2008 \\ Working Paper 2008-18
}

http://www.frbsf.org/publications/economics/papers/2008/wp08-18bk.pdf

The views in this paper are solely the responsibility of the authors and should not be interpreted as reflecting the views of the Federal Reserve Bank of San Francisco or the Board of Governors of the Federal Reserve System. 


\title{
LEARNING, ADAPTIVE EXPECTATIONS, AND TECHNOLOGY SHOCKS
}

\author{
KEVIN X.D. HUANG, ZHENG LIU, AND TAO ZHA
}

\begin{abstract}
This study explores the macroeconomic implications of adaptive expectations in a standard growth model. We show that the self-confirming equilibrium under adaptive expectations is the same as the steady state rational expectations equilibrium for all admissible parameter values, but that dynamics around the steady state are substantially different between the two equilibria. The differences are driven mainly by the dampened wealth effect and the strengthened intertemporal substitution effect, not by escapes emphasized by Williams (2003). Consequently, adaptive expectations can be an important source of frictions that amplify and propagate technology shocks and seem promising for generating plausible labor market dynamics.
\end{abstract}

\section{INTRODUCTION}

Learning models have been used for many macroeconomic applications (Sargent, 2007). ${ }^{1}$ We focus, in this paper, on yet another application in the context of a standard real business cycle model in which rational expectations are replaced by adaptive expectations. The stability of rational expectations under learning in real business cycle (RBC) models has been studied in the literature (Evans and Honkapohja, 2001; Bullard and Duffy, 2004; Carceles-Poveda and Giannitsarou, 2007; Eusepi and Preston, 2008). In a closely related paper, Williams (2003) considers a variety of standard

Date: September 7, 2008.

Key words and phrases. Self confirming equilibrium; amplification; labor market dynamics; wealth and substitution effects; hump-shaped responses.

JEL classification: E32, C62. Forthcoming in Economic Journal.

We thank the referees and the editor as well as Klaus Adam, James Bullard, Marty Eichenbaum, Martin Ellison, George Evans, Seppo Honkapohja, Selo Imrohoroglu, Bruce Preston, Tom Sargent, and Paolo Surico for helpful comments. The views expressed herein are those of the authors and do not necessarily reflect the views of the Federal Reserve Bank of Atlanta, the Federal Reserve Bank of San Francisco, or the Federal Reserve System.

${ }^{1}$ To give a few examples, Lucas (1986), Marcet and Sargent (1989), and Evans and Honkapohja (2001) recommend selecting rational expectations equilibria that are stable under least squares learning; Primiceri (2006), Sargent, Williams, and Zha (2006b), and Carboni and Ellison (2008) use learning mechanisms to explain the rise and fall of American inflation; Adam, Marcet, and Nicolini (2008) show how learning helps improve the fit of the model of asset pricing. 
learning rules in a RBC model. The learning rules that he considers do not separate agents' beliefs and their decision making. Agents are learning about the structural parameters in the reduced form of the model and the learning does not influence optimizing decisions. Under this type of learning, Williams (2003) finds that learning dynamics differ very little from rational expectations dynamics. Consequently, one would have concluded that learning dynamics do not teach us anything new, as compared to the rational expectations version of the RBC model.

In this paper, we reexamine this conclusion in the standard RBC model with both neutral and investment-specific technology shocks. Following the commonly-used learning mechanism studied by Marcet and Nicolini (2003) and Sargent, Williams, and Zha (2006a), we examine the implications of misspecified (i.e., under-parameterized) learning rules by separating agents' beliefs and their decision rules. ${ }^{2}$ Rational expectations are simply replaced by adaptive expectations, while all decision equations under rational expectations remain intact. We show that this slight departure from rational expectations has important ramifications. Specifically, we address the following questions:

- Does there exist a self-confirming equilibrium (SCE) in our learning environment? Is it unique?

- Are there strong escape dynamics away from the domain of attraction of the SCE?

- How does learning amplify the effects of technology shocks compared to rational expectations?

- How does learning affect the transmission mechanisms of technology shocks, especially in the labor market?

To answer these questions, we obtain closed form solutions for both the log-linearized rational expectations model and the corresponding learning model. These analytical solutions enable us to prove the existence and uniqueness of the SCE under all admissible parameterizations in our learning model. We further prove that the SCE coincides with the steady state rational expectations equilibrium (REE), but that learning dynamics are substantially different from rational expectations dynamics.

\footnotetext{
${ }^{2}$ Williams (2003) studies another misspecified learning in which agents do not know the true parameters of the production function. By assuming full depreciation of the capital stock, an i.i.d. technology process, and inelastic labor, he shows that learning leads to occasional, but recurrent, large deviations away from an SCE, called "escape dynamics." For other studies of escape dynamics, see Sargent (1999), Cho, Williams, and Sargent (2002), Kasa (2004), and Adam, Evans, and Honkapohja (in press).
} 
Unlike Marcet and Nicolini (2003), Williams (2003), and Sargent, Williams, and Zha (2006a), however, we show that learning dynamics are stationary and that the differences between learning dynamics and rational-expectations dynamics are not driven by escape dynamics.

These theoretical results enable one to draw macroeconomic implications from our learning model. The dynamic responses of output, consumption, investment, and labor hours, following a neutral technology shock, are substantially larger in the adaptive expectations model than in the rational expectations model. In the rational expectations equilibrium, hours change too little and the real wage fluctuates too much compared to the data. In contrast, learning amplifies the response of hours and dampens the response of the real wage. In our adaptive expectations model, agents form forecasts of future capital stock based on the past observations. Thus, introducing learning dampens the wealth effect of the neutral technology shock and strengthens the intertemporal substitution effect. Consequently, it helps amplify the effects of the neutral technology shock on output and investment and improve the model's predictions on the labor market dynamics. Introducing learning also helps amplify the effects of a biased technology shock.

The responses of hours to both types of technology shocks can be negative after initial periods in the learning model, whereas the hours responses to each of the two shocks are positive in the rational expectations model. The less persistent the shocks are, the more pronounced the negative responses of hours under learning can become. Furthermore, the learning model is more likely to generate hump-shaped responses of consumption, investment, real wage, and hours, the less persistent the shocks are.

To relate our work to a broader literature on learning, we also examine a sophisticated nonlinear learning rule that has a correct specification of the rational expectations solution. Consistent with the results reported by Carceles-Poveda and Giannitsarou (2007), we find that the transmission and propagation mechanisms of technology shocks depend crucially on initial conditions, the size of the shocks, and the size of the gain. We illustrate some cases where learning generates strong amplification effects of the technology shocks. In particular, we show that adaptive learning, acting as a friction, is capable of generating negative responses of hours to a neutral technology shock, as documented by some recent empirical studies (e.g., Galí (1999), Basu, Fernald, and Kimball (2006), Gambetti (2006)).

Overall, our results suggest that introducing adaptive expectations in the standard stochastic growth model can assign a more important role for technology shocks 
to generate fluctuations in key macroeconomic variables than under rational expectations. Introducing learning can be particular helpful in improving the model's predictions in the labor market.

\section{THE MODEL}

In this section, we describe the standard growth model with both neutral and biased technologies. The economy is populated by a continuum of infinitely lived and identical households. The representative household is endowed with a unit of time. The household derives utility from consumption and leisure, with the utility function

$$
\mathrm{E}_{0} \sum_{t=0}^{\infty} \beta^{t}\left\{\ln C_{t}-\xi \frac{L_{t}^{1+\eta}}{1+\eta}\right\},
$$

where $C_{t}$ denotes consumption, $L_{t}$ denotes labor hours, $\beta \in(0,1)$ denotes the subjective discount factor, and $\mathrm{E}_{0}$ denotes an expectation at the initial time 0 .

The economy is also populated by a continuum of identical, perfectly competitive firms. The representative firm has access to a constant returns to scale technology represented by the production function

$$
Y_{t}=K_{t-1}^{1-\alpha}\left(Z_{t} L_{t}\right)^{\alpha}
$$

where $Y_{t}$ denotes output, $K_{t-1}$ denotes capital input, and $L_{t}$ denotes labor input. The term $Z_{t}$ denotes the neutral technological change and follows the stochastic process

$$
Z_{t}=\lambda_{z}^{t} \nu_{t}
$$

where $\lambda_{z}$ is the trend component and $\nu_{t}$ is the stationary component that follows the $\mathrm{AR}(1)$ process

$$
\ln \nu_{t}=\rho_{\nu} \ln \nu_{t-1}+\varepsilon_{\nu t} .
$$

The persistence parameter $\rho_{\nu} \in(0,1]$ and the shock $\varepsilon_{\nu t}$ is a white noise process with mean zero and variance $\sigma_{\nu}^{2}$. The shock process specified in (3)-(4) implies that, if $0<\rho_{\nu}<1$, then the neutral technology follows a stationary stochastic process with a deterministic trend; if $\rho_{\nu}=1$, then the neutral technology follows a random walk process with a drift. ${ }^{3}$

The economy has an initial stock of capital denoted by $K_{-1}$. Capital stock evolves over time according to the law of motion

$$
K_{t}=(1-\delta) K_{t-1}+Q_{t} I_{t}
$$

\footnotetext{
${ }^{3}$ In the case with $\rho_{\nu}=1$, we have $Z_{t}=\lambda_{z}^{t} \nu_{t}$ and $\nu_{t}=\nu_{t-1} \exp \left(\varepsilon_{\nu t}\right)$, or equivalently, $Z_{t}=$ $Z_{t-1} \lambda_{z} \exp \left(\varepsilon_{\nu t}\right)$.
} 
where $K_{t}$ denotes the period- $t$ capital stock, $I_{t}$ denotes investment, $Q_{t}$ denotes the investment-specific technological change (the inverse of the relative price of investment goods, and the parameter $\delta \in(0,1)$ denotes the capital depreciation rate. As argued in Greenwood, Hercowitz, and Krusell (1997), the investment-specific technological change is an important driving force of the U.S. growth in the post-war period. Similar to the neutral technology, we assume that the investment-specific technology shock $Q_{t}$ follows the stochastic process

$$
Q_{t}=\lambda_{q}^{t} \mu_{t}
$$

where $\lambda_{q}$ is the trend component and $\mu_{t}$ is the stationary component that follows the $\operatorname{AR}(1)$ process

$$
\ln \mu_{t}=\rho_{\mu} \ln \mu_{t-1}+\varepsilon_{\mu t} .
$$

The persistence parameter $\rho_{\mu} \in(0,1)$ and the innovation term $\varepsilon_{\mu t}$ is white-noise process with mean zero and variance $\sigma_{\mu}^{2}$. Again, our specification of the $Q_{t}$ process here nests the random-walk process as a special case with $\rho_{\mu}=1$.

The aggregate resource constraint is given by

$$
C_{t}+I_{t}=Y_{t}
$$

\section{Equilibrium Allocation and Balanced Growth}

Since the model economy has perfect competition and no externality, the First Welfare Theorem applies. Thus, the equilibrium allocations are Pareto efficient and can be found by solving a social planner's problem.

The social planner maximizes the representative household's utility (1) subject to the resource constraint (8) and the capital law of motion (5). The first order conditions imply that

$$
\begin{aligned}
\xi L_{t}^{1+\eta} & =\alpha Y_{t} / C_{t} \\
1 & =\beta \mathrm{E}_{t}\left\{\frac{Q_{t}}{Q_{t+1}} \frac{C_{t}}{C_{t+1}}\left[1-\delta+Q_{t+1}(1-\alpha) \frac{Y_{t+1}}{K_{t}}\right]\right\} .
\end{aligned}
$$

On the balanced growth path, $C_{t}, I_{t}$, and $Y_{t}$ grow at the same rate of $\lambda_{z} \lambda_{q}^{(1-\alpha) / \alpha}$ while the capital stock $K_{t}$ grows at a faster rate of $\lambda_{z} \lambda_{q}^{1 / \alpha}$. We define the following 
stationary variables $^{4}$

$$
\tilde{Y}_{t}=\frac{Y_{t}}{Z_{t} Q_{t}^{(1-\alpha) / \alpha}}, \tilde{C}_{t}=\frac{C_{t}}{Z_{t} Q_{t}^{(1-\alpha) / \alpha}}, \tilde{I}_{t}=\frac{I_{t}}{Z_{t} Q_{t}^{(1-\alpha) / \alpha}}, \tilde{K}_{t}=\frac{K_{t}}{Z_{t} Q_{t}^{1 / \alpha}}
$$

Given these stationary variables, we can rewrite the equilibrium conditions (2), (5), (8), (9), and (10) as

$$
\begin{gathered}
\tilde{Y}_{t}\left(\frac{Z_{t}}{Z_{t-1}}\right)^{1-\alpha}\left(\frac{Q_{t}}{Q_{t-1}}\right)^{(1-\alpha) / \alpha}=\tilde{K}_{t-1}^{1-\alpha} L_{t}^{\alpha} \\
\tilde{K}_{t} \frac{Z_{t}}{Z_{t-1}}\left(\frac{Q_{t}}{Q_{t-1}}\right)^{1 / \alpha}=(1-\delta) \tilde{K}_{t-1}+\tilde{I}_{t} \frac{Z_{t}}{Z_{t-1}}\left(\frac{Q_{t}}{Q_{t-1}}\right)^{1 / \alpha}, \\
\tilde{C}_{t}+\tilde{I}_{t}=\tilde{Y}_{t} \\
\xi L_{t}^{1+\eta}=\alpha \tilde{Y}_{t} / \tilde{C}_{t}, \\
1=\beta \mathrm{E}_{t}\left[(1-\delta) \frac{\tilde{C}_{t}}{\tilde{C}_{t+1}} \frac{Z_{t}}{Z_{t+1}}\left(\frac{Q_{t}}{Q_{t+1}}\right)^{1 / \alpha}+(1-\alpha) \frac{\tilde{C}_{t}}{\tilde{C}_{t+1}} \frac{\tilde{Y}_{t+1}}{\tilde{K}_{t}}\right] .
\end{gathered}
$$

Denote $\lambda_{k} \equiv \lambda_{z} \lambda_{q}^{1 / \alpha}$. It follows from the above conditions that the steady state equilibrium can be described by the following equations

$$
\begin{gathered}
\lambda_{k}^{1-\alpha} \tilde{Y}=\tilde{K}^{1-\alpha} L^{\alpha}, \\
i_{k}=\frac{\tilde{I}}{\tilde{K}}=1-\frac{1-\delta}{\lambda_{k}}, \\
\tilde{C}+\tilde{I}=\tilde{Y} \\
\xi L^{1+\eta}=\alpha \tilde{Y} / \tilde{C} \\
y_{k}=\frac{\tilde{Y}}{\tilde{K}}=\frac{1}{\beta(1-\alpha)}\left[1-\frac{\beta(1-\delta)}{\lambda_{k}}\right],
\end{gathered}
$$

where $\tilde{Y}, \tilde{C}, \tilde{I}$, and $\tilde{K}$ are the steady state values of $\tilde{Y}_{t}, \tilde{C}_{t}, \tilde{I}_{t}$, and $\tilde{K}_{t}$. The consumptionoutput and investment-output ratios can derived from the above steady state conditions:

$$
\begin{gathered}
i_{y}=\frac{\tilde{I}}{\tilde{Y}}=\beta(1-\alpha) \frac{\lambda_{k}-(1-\delta)}{\lambda_{k}-\beta(1-\delta)}, \\
c_{y}=\frac{\tilde{C}}{\tilde{Y}}=1-i_{y} .
\end{gathered}
$$

\footnotetext{
${ }^{4} \mathrm{An}$ alternative approach to induce stationarity in the model is to detrend the variable by its deterministic trend. For instance, one can define $\tilde{X}_{t}=\frac{X_{t}}{\lambda_{x}^{t}}$, where $X_{t} \in\left\{Y_{t}, C_{t}, I_{t}, K_{t}\right\}$ and $\lambda_{x}$ is a function of $\lambda_{z}$ and $\lambda_{q}$. Our approach has an advantage in that it nests the model with stochastic trends (e.g., random walk processes) as a special case while the other approach does not.
} 
Log-linearizing the equilibrium conditions (11), (12), (13), (14), and (15) and rearranging the terms, we obtain the following five equations describing the production function, the law of motion for capital accumulation, the resource constraint, the optimal consumption-labor-supply decision, and the optimal investment decision:

$$
\begin{gathered}
\hat{y}_{t}-\alpha \hat{l}_{t}+(1-\alpha)\left(\frac{1}{\alpha} \Delta \hat{\mu}_{t}+\Delta \hat{\nu}_{t}\right)=(1-\alpha) \hat{k}_{t-1}, \\
\hat{k}_{t}-i_{k} \hat{i}_{t}+\left(1-i_{k}\right)\left(\alpha^{-1} \Delta \hat{\mu}_{t}+\Delta \hat{\nu}_{t}\right)=\left(1-i_{k}\right) \hat{k}_{t-1}, \\
c_{y} \hat{c}_{t}+i_{y} \hat{i}_{t}=\hat{y}_{t}, \\
\hat{y}_{t}=\hat{c}_{t}+(1+\eta) \hat{l}_{t}, \\
\beta(1-\alpha) y_{k} \hat{k}_{t}-\hat{c}_{t}+\left[1-\beta(1-\alpha) y_{k}\right]\left(\frac{\rho_{\mu}-1}{\alpha} \hat{\mu}_{t}+\left(\rho_{\nu}-1\right) \hat{\nu}_{t}\right)= \\
{\left[\beta(1-\alpha) c_{k}-1\right] E_{t} \hat{c}_{t+1}+\beta(1-\alpha) i_{k} E_{t} \hat{i}_{t+1},}
\end{gathered}
$$

where $\Delta$ is the first difference operator (e.g., $\Delta z_{t}=z_{t}-z_{t-1}$ ), the notation $\hat{x}_{t}$ denotes $\ln \tilde{X}_{t}-\ln \tilde{X}$ for $X=C, I, Y, K$ or $\ln X_{t}-\ln X$ for $X=L, i_{k}, c_{y}, i_{y}$, and $y_{k}$ are steady-state ratios defined in (17), (22), (21), (20), and $c_{k}=\frac{\tilde{C}}{\tilde{K}}$ is derived as

$$
\beta(1-\alpha)\left(c_{k}+1\right)=1-\frac{\alpha \beta(1-\delta)}{\lambda_{k}} .
$$

Definition 1. Admissible values of the deep parameters are $\beta \in(0,1), \eta \geq 0, \alpha \in$ $(0,1), \delta \in[0,1], \lambda_{z} \geq 1$, and $\lambda_{q} \geq 1$.

In the literature, dynamics are often simulated for a particular set of admissible values of the deep parameters by numerically solving the rational-expectations equilibrium system given by the above conditions. We shall show, however, that the equilibrium characterized by (23)-(27) can be solved analytically for all admissible values of the deep parameters. The crucial step is to derive a stochastic process for capital, as stated in the following proposition.

Proposition 1. The equilibrium solution for capital satisfies the following second-order stochastic difference equation:

$$
\hat{k}_{t}=\gamma_{1} E_{t} \hat{k}_{t+1}+\gamma_{2} \hat{k}_{t-1}+\gamma_{\mu 1} \hat{\mu}_{t}+\gamma_{\nu 1} \hat{\nu}_{t}+\gamma_{\mu 2} \hat{\mu}_{t-1}+\gamma_{\nu 2} \hat{\nu}_{t-1},
$$

where the coefficients $\gamma_{1}, \gamma_{2}, \gamma_{\mu 1}, \gamma_{\nu 1}, \gamma_{\mu 2}$, and $\gamma_{\nu 2}$ are reported in Appendix A. Further, as we show in the Appendix, the structural parameters (which are functions of the deep parameters) satisfy the restrictions that $\gamma_{1}>0, \gamma_{2}>0$, and $\gamma_{1}+\gamma_{2}<1$. 
Proposition 1 is the key to obtaining all of our theoretical results, as is shown in the next section.

\section{REE vs. SCE: TheORETiC REsults}

In this section, we derive the closed-form solutions for both the REE and the SCE. The key is to solve (29); the solution depends on how agents form expectations of the endogenous accumulation process of capital. Once this solution is obtained, it is relatively straightforward to derive the closed-form solutions for the other variables, which are reported in Appendix A.

For the REE solution, we have the following result.

Proposition 2. The solution to the second-order differential equation (29) under the rational expectations assumption is

$$
\hat{k}_{t}=a \hat{k}_{t-1}+b \hat{\nu}_{t}+c \hat{\mu}_{t}+d \hat{\nu}_{t-1}+e \hat{\mu}_{t-1}
$$

where

$$
\begin{gathered}
a=\frac{1-\sqrt{1-4 \gamma_{1} \gamma_{2}}}{2 \gamma_{1}}, \quad b=\frac{\gamma_{1} d+\gamma_{\nu 1}}{1-\left(\rho_{\nu}+a\right) \gamma_{1}}, \quad c=\frac{\gamma_{1} e+\gamma_{\mu 1}}{1-\left(\rho_{\mu}+a\right) \gamma_{1}} \\
d=\frac{\gamma_{\nu 2}}{1-\gamma_{1} a}, \quad e=\frac{\gamma_{\mu 2}}{1-\gamma_{1} a} .
\end{gathered}
$$

Furthermore, this solution is stationary and unique.

Proof. See Appendix C.

If we replace the capital-accumulation Euler equation (27) by the closed-form expression (30), the system of equations (23)-(26) and (30) constitutes a reduced-form solution to the rational-expectations model.

Given the shock processes and an initial condition for capital (30) gives the dynamic solution for capital. For a comparison with the SCE solution, this dynamic solution can be expressed as

$$
\hat{k}_{t}=b \varepsilon_{\nu, t}+c \varepsilon_{\mu, t}+\sum_{i=1}^{\infty}\left(b b_{i}+d b_{i-1}\right) \varepsilon_{\nu, t-i}+\sum_{i=1}^{\infty}\left(c c_{i}+e c_{i-1}\right) \varepsilon_{\mu, t-i}
$$

where for all $i \geq 0$,

$$
b_{i}=\sum_{j=0}^{i} a^{i-j} \rho_{\nu}^{j}, \quad \text { while if } \quad \rho_{\nu} \neq a \quad \text { then } \quad b_{i}=\frac{a^{i+1}-\rho_{\nu}^{i+1}}{a-\rho_{\nu}}
$$




$$
c_{i}=\sum_{j=0}^{i} a^{i-j} \rho_{\mu}^{j}, \quad \text { while if } \quad \rho_{\mu} \neq a \quad \text { then } \quad c_{i}=\frac{a^{i+1}-\rho_{\mu}^{i+1}}{a-\rho_{\mu}} ;
$$

We now assume that agents have adaptive expectations. We follow Marcet and Nicolini (2003) and Sargent, Williams, and Zha (2006a) to replace $E_{t} \hat{k}_{t+1}$ by $\hat{E}_{t} \hat{k}_{t+1}$ such that

$$
\hat{E}_{t} \hat{k}_{t+1}=\hat{\beta}_{t}
$$

Agents update their beliefs $\hat{\beta}_{t}$ using the following constant-gain learning (CGL) algorithm:

$$
\hat{\beta}_{t}=\hat{\beta}_{t-1}+g\left(\hat{k}_{t-1}-\hat{\beta}_{t-1}\right),
$$

where $0<g<1$ is a gain representing how fast past observations are discounted in the learning regression.

The dynamics of $\hat{k}_{t}$ produced by (29) under the above learning algorithm (32) follow the process

$$
\hat{k}_{t}=\gamma_{1} \hat{\beta}_{t}+\gamma_{2} \hat{k}_{t-1}+\gamma_{\nu 1} \hat{\nu}_{t}+\gamma_{\mu 1} \hat{\mu}_{t}+\gamma_{\nu 2} \hat{\nu}_{t-1}+\gamma_{\mu 2} \hat{\mu}_{t-1}
$$

In self-confirming equilibrium, beliefs are not contradicted by observations along the equilibrium path (Sargent, 1999). To find an SCE is to solve a fixed-point problem. For our model, the solution to the SCE is to find the fixed point $\hat{\beta}$ that solves the orthogonality condition

$$
E\left[\hat{k}_{t}(\hat{\beta})-\hat{\beta}\right]=0
$$

where $E()$ is a mathematical unconditional expectation operator and $\hat{k}_{t}$ itself is a function of the belief $\hat{\beta}$ in self-confirming equilibrium such that

$$
\hat{k}_{t}(\hat{\beta})=\gamma_{1} \hat{\beta}+\gamma_{2} \hat{k}_{t-1}(\hat{\beta})+\gamma_{\nu 1} \hat{\nu}_{t}+\gamma_{\mu 1} \hat{\mu}_{t}+\gamma_{\nu 2} \hat{\nu}_{t-1}+\gamma_{\mu 2} \hat{\mu}_{t-1}
$$

Proposition 3. As $g \rightarrow 0$, the belief sequence $\left\{\hat{\beta}_{t}\right\}$ in (32) converges weakly to the unique and stationary SCE given by $\hat{\beta}=0$ for all admissible values of the deep parameters.

Proof. From (33) one can see that $\hat{k}_{t}$ is a function of current and past beliefs and fundamental shocks. We denote this function as $\kappa()$ such that

$$
\hat{k}_{t}=\kappa\left(\hat{\beta}_{t}, \hat{\beta}_{t-1}, \ldots, \nu_{t}, \nu_{t-1}, \ldots, \mu_{t}, \mu_{t-1}, \ldots\right) .
$$

Denote

$$
\begin{aligned}
\tilde{\kappa}\left(\hat{\beta}_{t}, \hat{\beta}_{t-1}, \ldots, \nu_{t}, \nu_{t-1}, \ldots, \mu_{t}, \mu_{t-1}, \ldots\right) \\
=\kappa\left(\hat{\beta}_{t}, \hat{\beta}_{t-1}, \ldots, \nu_{t}, \nu_{t-1}, \ldots, \mu_{t}, \mu_{t-1}, \ldots\right)-\hat{\beta}_{t} .
\end{aligned}
$$


We can then rewrite the CGL algorithm (32) as

$$
\hat{\beta}_{t}=\hat{\beta}_{t-1}+g \tilde{\kappa}\left(\hat{\beta}_{t}, \hat{\beta}_{t-1}, \ldots, \nu_{t}, \nu_{t-1}, \ldots, \mu_{t}, \mu_{t-1}, \ldots\right)
$$

To prove that (34) holds at $\hat{\beta}=0$ and the fixed point $\hat{\beta}=0$ is unique, we denote the left-hand-side term in (34) by

$$
G(\hat{\beta})=E \tilde{\kappa}\left(\hat{\beta}, \hat{\beta}, \ldots, \nu_{t}, \nu_{t-1}, \ldots, \mu_{t}, \mu_{t-1}, \ldots\right) .
$$

Under our assumptions, it follows from Kushner and Yin (1997) that as $g \rightarrow 0$, the beliefs $\hat{\beta}_{t}$ in $(35)$ converge weakly to the solution of the ordinary differential equation (ODE)

$$
\dot{\hat{\beta}}=G(\hat{\beta}) \text {. }
$$

One can further show that

$$
G(\hat{\beta})=\left(\frac{\gamma_{2}+\gamma_{1}-1}{1-\gamma_{2}}\right) \hat{\beta}
$$

Since $\gamma_{1}>0, \gamma_{2}>0$, and $\gamma_{2}+\gamma_{1}<1$, the ODE has a unique fixed point at $\hat{\beta}=0$. The ODE is stable since $\left(\gamma_{2}+\gamma_{1}-1\right) /\left(1-\gamma_{2}\right)<0$.

As one can see from Proposition 3, the SCE is exactly the same as the rational expectations steady state. Since an SCE is a limit of adaptive (learning) dynamics, it is important to characterize these dynamics and to study whether they are significantly different from dynamics under rational expectations. We rewrite the stochastic processes (32) and (33) as

$$
\left[\begin{array}{l}
\hat{\beta}_{t} \\
\hat{k}_{t}
\end{array}\right]=\left[\begin{array}{cc}
1-g & g \\
(1-g) \gamma_{1} & \gamma_{2}+g \gamma_{1}
\end{array}\right]\left[\begin{array}{c}
\hat{\beta}_{t-1} \\
\hat{k}_{t-1}
\end{array}\right]+\left[\begin{array}{cc}
0 & 0 \\
\gamma_{\nu 1} & \gamma_{\mu 1}
\end{array}\right]\left[\begin{array}{c}
\hat{\nu}_{t} \\
\hat{\mu}_{t}
\end{array}\right]+\left[\begin{array}{cc}
0 & 0 \\
\gamma_{\nu 2} & \gamma_{\mu 2}
\end{array}\right]\left[\begin{array}{c}
\hat{\nu}_{t-1} \\
\hat{\mu}_{t-1}
\end{array}\right] .
$$

Given the initial belief $\hat{\beta}_{-1}$, the initial capital stock $\hat{k}_{-1}$, and the shock processes, the bivariate autoregressive process (36) determines the belief and capital dynamics jointly; then, (23)-(26) in Section III, or (A1)-(A4) in Appendix A, determine the dynamics of investment, labor, output, and consumption. Clearly this learning model is linear and consequently the impulse responses do not depend on initial conditions. In Section VI, we discuss an alternative learning rule that nests the rational-expectations solution and show that the results do depend on initial conditions and the size of the gain.

We now provide a result showing that the linear system represented by the above learning model is stationary. 
Proposition 4. The learning dynamics, described by (23)-(26) and (36) for $g \in(0,1)$, are stationary for all admissible values of the deep parameters.

Proof. Given (A1)-(A4) in Appendix A that characterize the dynamics of investment, labor, output, and consumption as a function of $\hat{k}_{t}$, it suffices to show that (36) is a stationary process. The two characteristic roots of the $2 \times 2$ coefficient matrix of $\hat{\beta}_{t-1}$ and $\hat{k}_{t-1}$ on the right-hand side of (36) are

$$
\begin{aligned}
& \lambda_{1}=\frac{\left(1-g+\gamma_{2}+g \gamma_{1}\right)-\sqrt{\left(1-g+\gamma_{2}+g \gamma_{1}\right)^{2}-4(1-g) \gamma_{2}}}{2}, \\
& \lambda_{2}=\frac{\left(1-g+\gamma_{2}+g \gamma_{1}\right)+\sqrt{\left(1-g+\gamma_{2}+g \gamma_{1}\right)^{2}-4(1-g) \gamma_{2}}}{2} .
\end{aligned}
$$

Since $\gamma_{1}>0, \gamma_{2}>0$, and $\gamma_{1}+\gamma_{2}<1$ for all admissible values of the deep parameters, it follows that both $\lambda_{1}$ and $\lambda_{2}$ are real numbers and for any $g \in(0,1), 0<\lambda_{1}<\lambda_{2}<1$. Hence, the adaptive process for $\left\{\hat{\beta}_{t}, \hat{k}_{t}\right\}$, given by (36), is stationary.

Proposition 4 implies that the learning dynamics studied in this paper remain in the domain of attraction of the SCE (the rational expectations steady state) and thus the probability of escapes from the SCE is very small.

To assess how different the learning dynamics differ from dynamics under rational expectations, we derive the belief and capital dynamics under the CGL as

$$
\begin{gathered}
\left(1-\lambda_{1} L\right)\left(1-\lambda_{2} L\right) \hat{\beta}_{t}=g\left(\gamma_{\nu 1} \hat{\nu}_{t-1}+\gamma_{\mu 1} \hat{\mu}_{t-1}+\gamma_{\nu 2} \hat{\nu}_{t-2}+\gamma_{\mu 2} \hat{\mu}_{t-2}\right), \\
\left(1-\lambda_{1} L\right)\left(1-\lambda_{2} L\right) \hat{k}_{t}=[1-(1-g) L]\left(\gamma_{\nu 1} \hat{\nu}_{t}+\gamma_{\mu 1} \hat{\mu}_{t}+\gamma_{\nu 2} \hat{\nu}_{t-1}+\gamma_{\mu 2} \hat{\mu}_{t-1}\right),
\end{gathered}
$$

where $L$ is the lag operator. It follows from (37) that

$$
\begin{aligned}
\hat{\beta}_{t}=g \sum_{i=1}^{\infty} \sum_{j=1}^{i} \frac{\lambda_{1}^{j}-\lambda_{2}^{j}}{\lambda_{1}-\lambda_{2}}\left(\gamma_{\nu 1} \rho_{\nu}^{i-j} \varepsilon_{\nu, t-i}+\gamma_{\mu 1} \rho_{\mu}^{i-j} \varepsilon_{\mu, t-i}\right. & \\
& \left.+\gamma_{\nu 2} \rho_{\nu}^{i-j} \varepsilon_{\nu, t-1-i}+\gamma_{\mu 2} \rho_{\mu}^{i-j} \varepsilon_{\mu, t-1-i}\right) .
\end{aligned}
$$

This can be simplified to

$$
\begin{aligned}
\hat{\beta}_{t} & =g \gamma_{\nu 1} \varepsilon_{\nu, t-1}+g \sum_{i=2}^{\infty}\left[\gamma_{\nu 1} \frac{\lambda_{1}^{i}-\lambda_{2}^{i}}{\lambda_{1}-\lambda_{2}}+\left(\gamma_{\nu 1}+\gamma_{\nu 2} \rho_{\nu}^{-1}\right) \sum_{j=1}^{i-1} \frac{\lambda_{1}^{j}-\lambda_{2}^{j}}{\lambda_{1}-\lambda_{2}} \rho_{\nu}^{i-j}\right] \varepsilon_{\nu, t-i} \\
& +g \gamma_{\mu 1} \varepsilon_{\mu, t-1}+g \sum_{i=2}^{\infty}\left[\gamma_{\mu 1} \frac{\lambda_{1}^{i}-\lambda_{2}^{i}}{\lambda_{1}-\lambda_{2}}+\left(\gamma_{\mu 1}+\gamma_{\mu 2} \rho_{\mu}^{-1}\right) \sum_{j=1}^{i-1} \frac{\lambda_{1}^{j}-\lambda_{2}^{j}}{\lambda_{1}-\lambda_{2}} \rho_{\mu}^{i-j}\right] \varepsilon_{\mu, t-i} .
\end{aligned}
$$


If $\rho_{\nu} \neq \lambda_{1}$ or $\lambda_{2}$, and $\rho_{\mu} \neq \lambda_{1}$ or $\lambda_{2}$, then it simplifies further to

$$
\begin{aligned}
& \hat{\beta}_{t}=g \gamma_{\nu 1} \varepsilon_{\nu, t-1}+g \sum_{i=1}^{\infty} {\left[\gamma_{\nu 1} \frac{\lambda_{1}^{i+1}-\lambda_{2}^{i+1}}{\lambda_{1}-\lambda_{2}}\right.} \\
&\left.+\left(\rho_{\nu} \gamma_{\nu 1}+\gamma_{\nu 2}\right)\left(\frac{\lambda_{1}}{\lambda_{1}-\lambda_{2}} \frac{\lambda_{1}^{i}-\rho_{\nu}^{i}}{\lambda_{1}-\rho_{\nu}}-\frac{\lambda_{2}}{\lambda_{1}-\lambda_{2}} \frac{\lambda_{2}^{i}-\rho_{\nu}^{i}}{\lambda_{2}-\rho_{\nu}}\right)\right] \varepsilon_{\nu, t-1-i} \\
&+g \gamma_{\mu 1} \varepsilon_{\mu, t-1}+g \sum_{i=1}^{\infty}\left[\gamma_{\mu 1} \frac{\lambda_{1}^{i+1}-\lambda_{2}^{i+1}}{\lambda_{1}-\lambda_{2}}\right. \\
&\left.+\left(\rho_{\mu} \gamma_{\mu 1}+\gamma_{\mu 2}\right)\left(\frac{\lambda_{1}}{\lambda_{1}-\lambda_{2}} \frac{\lambda_{1}^{i}-\rho_{\mu}^{i}}{\lambda_{1}-\rho_{\mu}}-\frac{\lambda_{2}}{\lambda_{1}-\lambda_{2}} \frac{\lambda_{2}^{i}-\rho_{\mu}^{i}}{\lambda_{2}-\rho_{\mu}}\right)\right] \varepsilon_{\mu, t-1-i} .
\end{aligned}
$$

On the other hand, we can compute the rational expectations from (31) as

$$
\begin{aligned}
& E_{t} \hat{k}_{t+1}=\left[b\left(a+\rho_{\nu}\right)+d\right] \varepsilon_{\nu, t}+\left[c\left(a+\rho_{\mu}\right)+e\right] \varepsilon_{\mu, t} \\
& +\sum_{i=1}^{\infty}\left(b b_{i+1}+d b_{i}\right) \varepsilon_{\nu, t-i}+\sum_{i=1}^{\infty}\left(c c_{i+1}+e c_{i}\right) \varepsilon_{\mu, t-i} .
\end{aligned}
$$

A comparison of (40) and (41) shows that, although the SCE is the same as the steady state REE, the dynamics of the beliefs $\hat{\beta}_{t}$ can be different from the dynamics of the expectations $E_{t} \hat{k}_{t+1}$. These differences lead to quantitatively important differences in the dynamics of other macroeconomic variables, as we show in the next section.

\section{REE vs. SCE: Transmission of Technology Shocks}

We now analyze the transmission mechanisms of the model under both rational and adaptive expectations. We discuss simulated results based on a few sets of parameter values, but the quantitative differences between learning and rational expectations dynamics exist for a wide range of values. The model parameters include $\beta$, the subjective discount factor; $\alpha$, the labor share of income; $\delta$, the capital depreciation rate; $\eta$, the inverse Frisch elasticity of labor supply; $\lambda_{z}$ and $\lambda_{q}$, the average growth rate of the neutral and biased technologies; $\xi$, the weight parameter in the preferences for leisure; $\rho_{\nu}, \rho_{\mu}, \sigma_{\nu}$, and $\sigma_{\mu}$, the parameters controlling the shock processes, and $g$, the constant gain in the learning process.

V.1. Benchmark parameter values. Table 1 summarizes the benchmark parameter values that we use for our simulations. The model that we have in mind has a quarterly frequency. We set $\alpha=0.7$, corresponding to a labor income share of $70 \%$. We set $\lambda_{q}=1.008$ such that the investment-specific technology grows at an annual rate of $3.2 \%$, as suggested by Greenwood, Hercowitz, and Krusell (1997). We set $\lambda_{z}=1.0016$ such that, given our value of $\lambda_{q}$ and $\alpha$, real per capita GDP grows at 
an annual rate of $2 \%$ on the path of balanced growth. ${ }^{5}$ We set $\delta=0.03$, so that the annual depreciation rate of capital is $12 \%$. We follow the business cycle literature and set $\beta=0.99$. We use a value of $\xi=3.17$ so that the steady state working hours are about $1 / 3$ of the representative agent's time endowment. We follow Hansen (1985) and Rogerson (1988) and assume that labor is indivisible, implying that $\eta=0$. For the parameters in the shock processes, we set $\rho_{\nu}=\rho_{\mu}=0.95, \sigma_{\nu}=0.01$, and $\sigma_{\mu}=0.005$. These standard-deviation values are consistent with the estimates in the empirical literature (e.g., Liu, Waggoner, and Zha (2008)). Finally, we set the gain $g=0.05$ in the learning process. This value is in the range of empirical estimates found in Sargent, Williams, and Zha (2006a). We have also experimented with other gain values and find that, under our benchmark learning rule (32), the results do not change much.

V.2. Amplification effects. To understand the role of introducing learning in transmitting the two types of technology shocks, we examine the impulse responses of macroeconomic variables in the model to each shock.

V.2.1. Neutral technology shock. Figure 1 displays the impulse responses of several key macroeconomic variables, including output, consumption, investment, the real interest rate, labor hours, the real wage, the expectation (or the belief) of the nextperiod capital, and the current-period capital stock, following a positive one-standarddeviation shock to the neutral technology under our benchmark parameter values. The solid lines represent the responses under rational expectations and the dashed lines represent the responses under adaptive expectations.

The responses of aggregate variables to a neutral technology shock in the rational expectations model should be familiar to a student of real business cycle studies. As the solid line in the figure shows, output rises on impact and declines gradually. Consumption, investment, hours, the real wage, and the real interest rate all comove with output. In the impact period, consumption responds less and investment responds more than does output. These patterns of responses are consistent with the stylized facts about business cycles.

A well documented difficulty facing the standard RBC model with rational expectations lies in the labor market dynamics (Christiano and Eichenbaum, 1992). The RBC model typically fails to generate the observed large responses of labor hours and small responses of the real wage following a neutral technology shock. In the RBC model, a positive neutral technology shock raises the demand for labor at any given

\footnotetext{
${ }^{5}$ The average growth rate for output in the model is given by $\lambda_{z} \lambda_{q}^{(1-\alpha) / \alpha}$.
} 
real wage so that the labor demand schedule shifts out, creating a substitution effect. Thus, holding the labor supply schedule unchanged, the substitution effect drives up both hours and the real wage. In the mean time, since the shock is persistent and therefore raises future productivity, it creates a wealth effect that raises current consumption and thus shifts the labor supply curve up. The wealth effect partially cancels out the substitution effect on hours, rendering the responses of equilibrium hours small; meanwhile, the wealth effect reinforces the substitution effect on the real wage, pushing up the equilibrium wage sharply. As shown by Hansen (1985) and Rogerson (1988), labor indivisibility flattens the labor supply curve and thus magnifies the substitution effect following the positive neutral technology shock, although the wealth effect still makes the real wage rise sharply. ${ }^{6}$ As is evident in Figure 1 and in Table 2, the model with rational expectations implies that the initial response of hours is about $67 \%$ of that of output and the magnitude of the real wage response about $33 \%$ of that of output response. Indeed, as shown in Table 2 , in the rational expectations model, the cumulative responses of hours at longer forecasting horizons (from 4 quarter through 24 quarters) are less than $58 \%$ and those of the real wages are more than $42 \%$ relative to the output responses.

Introducing learning helps alleviate some of the problems for the RBC model, especially for the labor market variables. The dashed lines in Figure 1 display the impulse responses of the aggregate variables in the model with adaptive expectations following a positive neutral technology shock. As in the rational expectations model, the shock raises the demand for labor at any given wage and this substitution effect leads to a rise in both hours and the real wage. Unlike the rational expectations model, however, the wealth effect is dampened because agents form expectations about future productivity and capital based on past observations. Consequently, on impact, consumption does not rise as much and thus the labor supply curve does not shift as much as in the rational expectations model. By dampening the wealth effect of the shock, the learning mechanism leads to a greater response of equilibrium hours and a smaller response of equilibrium real wage than those in the rational expectations model. Table 2 confirms these findings: in the model with adaptive expectations, the cumulative responses of hours relative to output for all forecasting horizons (up to 24 quarters) are much larger while the cumulative responses of the real wage relative to

\footnotetext{
${ }^{6}$ If the Frisch elasticity of labor supply is small (i.e., if $\eta$ is large), as the micro evidence suggests, the labor supply curve would be steep and the substitution effect would be small. Consequently, the response of hours would be smaller and the response of the real wage would be even larger than in the model with indivisible labor.
} 
output are, at least in the short run (up to 4 quarters), much smaller than those in the rational expectations model .

To the extent that some other frictions such as habit formation can also slow down the adjustment in consumption, one might wonder whether or not habit formation can help alleviate the labor market puzzle as does our learning mechanism. Lettau and Uhlig (2000) show that habit formation slows down the adjustments of consumption for all periods, not just for the current period. As the agent desires slow adjustments of consumption in all future periods, he does not want to work hard in the current period to accumulate capital. Thus, a positive neutral technology shock leads to a small increase in hours and a large increase in the marginal product of labor and the real wage. In this sense, introducing habit formation can actually deepen the labor market puzzle. In contrast, the model with adaptive expectations that we consider here contains a very different propagation mechanism and helps alleviate the labor market puzzle.

Introducing adaptive expectations in the model also helps amplify the responses of other aggregate variables. As shown in Figure 1, under adaptive expectations, the sharp rise in hours following the positive productivity shock leads to a sharp rise in output. As consumption does not change much on impact, investment rises sharply. The amplified response of investment implies amplified responses of the capital stock and the beliefs of future capital stocks relative to the rational expectations model.

In summary, following a neutral technology shock, introducing learning amplifies the response of hours and dampens the responses of the real wage. Furthermore, learning helps amplify the effects of the neutral technology shock on output, investment, and capital.

V.2.2. Biased technology shock. There is a large literature on the macroeconomic effects of investment-specific technology shocks in the context of rational-expectations. Examples include Greenwood, Hercowitz, and Krusell (2000), Krusell, Ohanian, RíosRull, and Violante (2000), Fisher (2006), and He and Liu (2008). In this section, we examine the effects of biased technology shocks in the context of adaptive expectations.

In Figure 2, we plot the impulse responses of the same set of macroeconomic variables following a positive one-standard-deviation shock to the biased technology. In both the rational expectations model (solid lines) and the adaptive expectations model (dashed lines), the shock leads to a rise in output, investment, hours, capital stock, and the real interest rate, and a short-run decline in consumption and the real wage. 
As the biased shock raises the efficiency of investment, current investment becomes cheaper relative to consumption. Thus, this type of shock, unlike the neutral technology shock, shifts resources from consumption to investment. Consequently, investment rises and consumption declines for several periods. The decline in consumption shifts the labor supply curve down. Since the neutral technology stays unchanged and aggregate capital stock is predetermined, the labor demand curve does not shift. Thus, the downward shift of the labor supply curve lowers the real wage and raises equilibrium hours. The rise in labor hours helps produce more output and raise the marginal product of capital, so that the real interest rate rises as well. This mechanism operates under both rational expectations and adaptive expectations.

The patterns of the impulse responses following a positive biased technology shock are broadly consistent with the empirical evidence provided by Altig, Christiano, Eichenbaum, and Linde (2004), except that consumption and the real wage in the model do not comove with output whereas consumption is weakly procyclical and the real wage is acyclical in the data based on VAR studies. The lack of comovement in the model is not surprising since Barro and King (1984) show that the standard one-sector growth model can generate comovement only in the presence of contemporaneous total factor productivity shocks (i.e., the neutral technology shocks in our model). It is possible to fix the comovement problem by introducing several sources of frictions in the model (see, for example, Jaimovich and Rebelo (2008)). We do not introduce other frictions because we would like to isolate the role of learning, which itself acts as a friction, in propagating technology shocks.

The main difference between the learning model and the rational expectations model is that, with learning in place of full rationality, agents do not perfectly foresee the increase in the future level of investment technology. They respond to the persistent shock as though it had only a temporary effect. The wealth effect is thus dampened and the intertemporal substitution effect strengthened. Consequently, in the learning model, the biased technology shock leads to a greater rise in investment and a greater decline in consumption than that in the rational expectations model. The sharp decline in consumption amplifies the decline in the real wage and the rise in hours. The amplified increase in hours in turn leads to a sharp rise in output and thus in the real interest rate. These patterns are shown in Figure 2.

In summary, introducing learning can substantially amplify the responses of all the aggregate variables following a biased technology shock. Overall, relaxing the assumption of perfect rationality helps give a larger role to both neutral and biased technology shocks in shaping business cycles. 
V.3. Less persistent shocks. Since the transmission of the shocks in the model with adaptive expectations works through the muted wealth effect, the quantitative importance of learning should depend on the persistence of the shock. To understand to what extent the propagation mechanism in the learning model depends on the persistence of the shocks, we consider the case with less persistent shocks. In particular, we set $\rho_{\nu}=\rho_{\mu}=0.7$ (instead of 0.95 ) and compute the impulse responses following each of the two types of technology shocks.

Figure 3 displays the impulse responses of the key macroeconomic variables to a positive one-standard-deviation shock to the neutral technology. ${ }^{7}$ The responses under rational expectations are denoted by the solid lines and those under adaptive expectations are denoted by the dashed lines. Since the shock is less persistent, the wealth effect is weaker so that, in the rational expectations model, the rise in consumption is smaller and the rise in hours is larger than that under the benchmark parameter values. With the less persistent shock and the weaker wealth effect, introducing adaptive learning dampens the response of the real wage and amplifies the responses of other aggregate variables, but to a lesser extent than in the benchmark case. These results are evident by comparing Figure 3 with Figure 1.

Moreover, with the less persistent shock, the responses of both consumption and the real wage display a clear hump shape; the responses of investment, hours, and the real interest rate all display an inverted hump shape; and output rises in the impact period and declines monotonically thereafter. Under adaptive expectations, the representative agent is backward looking when forming expectations. In the impact period, the wealth effect of the shock is muted; the intertemporal substitution effect induced by the rise in the real interest rate makes consumption more expensive and saving more attractive. Thus, in the short run, consumption rises by less and investment rises by more than in the rational expectations model. Overtime, however, the agent learns about the wealth effect of the positive technology shock while the intertemporal substitution effect becomes weaker as the real interest rate goes back to its steady state. Thus, consumption rises further before it begins to decline back to the steady state. The rise in consumption shifts the labor supply curve up and thus lowers labor hours and raises the real wage. As consumption climbs to its peak over time, hours and investment fall to the trough and the real wage rises to the peak.

\footnotetext{
${ }^{7}$ To conserve space, we do not report the impulse responses following the biased technology shock here. The responses are qualitatively similar to those in the benchmark model, although the amplification effects of learning become smaller as the shock is less persistent than that in the benchmark model.
} 
Since output falls back to the steady state over time, consumption, investment, and hours return gradually to the steady state.

In summary, with less persistent shocks, the wealth effect in the rational expectations model becomes weaker and accordingly the amplification effect of adaptive expectations become weaker as well. The adaptive expectations model generates pronounced hump-shaped responses while the rational expectations model does not.

\section{Vi. An Alternative Learning Rule}

One interesting question is whether our main findings hinge on the particular learning rule (32). There are many alternative learning mechanisms, such as least-square learning (Evans and Honkapohja, 2001), Bayesian updating through Kalman filtering (Sargent and Williams, 2005), and signal extraction when agents are confused between shocks to the level or to the growth rate of the technology (Edge, Laubach, and Williams, 2007). We focus on one particular constant-gain learning rule that has the same specification as the rational expectations solution (30). Specifically, we replace $E_{t} \hat{k}_{t+1}$ by $\hat{E}_{t} \hat{k}_{t+1}$ such that

$$
\hat{E}_{t} \hat{k}_{t+1}=\hat{x}_{t}^{\prime} \alpha_{t \mid t-1}
$$

where

$$
\hat{x}_{t}=\left[\begin{array}{l}
\hat{k}_{t} \\
\hat{\nu}_{t} \\
\hat{\mu}_{t}
\end{array}\right] \text {. }
$$

Agents update their beliefs $\alpha_{t+1 \mid t}$ using the following recursive algorithm:

$$
\begin{gathered}
\alpha_{t+1 \mid t}=\alpha_{t \mid t-1}+g H_{t} \hat{x}_{t-1}\left(\hat{k}_{t}-\hat{x}_{t-1}^{\prime} \alpha_{t \mid t-1}\right), \\
H_{t}^{-1}=H_{t-1}^{-1}+g\left(\hat{x}_{t-1} \hat{x}_{t-1}^{\prime}-H_{t-1}^{-1}\right) .
\end{gathered}
$$

As $g \rightarrow 0$, the equilibrium under this adaptive learning approaches the rational expectations equilibrium and is therefore E-stable in the usual sense of Evans and Honkapohja (2001). Unlike the benchmark learning rule studied in Section IV, this alternative rule is updated nonlinearly and thus short-run dynamic results can be quite different for different initial conditions. This point is discussed in CarcelesPoveda and Giannitsarou (2007). One particular type of initial conditions studied by Carceles-Poveda and Giannitsarou (2007) is to generate the initial data, $\left\{\hat{x}_{0}, \ldots, \hat{x}_{t_{0}}\right\}$, 
from the equilibrium solution to the rational-expectations model. ${ }^{8}$ The initial conditions can then be computed as

$$
\begin{gathered}
\alpha_{t_{0}+1 \mid t_{0}}=H_{t_{0}} g \sum_{s=0}^{t_{0}-1}(1-g)^{t_{0}-1-s} \hat{x}_{s} \hat{k}_{s+1}, \\
H_{t_{0}}^{-1}=g \sum_{s=0}^{t_{0}-1}(1-g)^{t_{0}-1-s} \hat{x}_{s} \hat{x}_{s}^{\prime} .
\end{gathered}
$$

With these initial conditions, one can update the beliefs recursively according to (42) and (43). We simulate the model under the benchmark parameter values summarized in Table 1 and we also examine the sensitivity of the learning equilibrium to changes in the initial conditions and the size of the gain parameter.

When the gain is small and the initial data set is large, the differences between the dynamics under learning and those under rational expectations tend to be very small. Figure 4 displays an example of impulse responses to one-standard-deviation neutral technology shock with $g=0.001$ and $t_{0}=10000$. As the figure shows, the learning model and the rational expectations model generate quantitatively similar responses. This result is consistent with the findings in Williams (2003) and Carceles-Poveda and Giannitsarou (2007). In a recent paper, Eusepi and Preston (2008) show that learning can nonetheless amplify the dynamic responses if one relaxes the standard assumption that agents use only one-period ahead forecasts to form their beliefs.

We argue that even with the standard learning mechanism (42)-(43), different gain values or different initial conditions can produce qualitatively different impulse responses. In this section we focus on cases where adaptive learning under this sophisticated rule can amplify the dynamic responses of aggregate variables to a neutral technology shock, generate negative responses of hours, and produce procyclical movements of consumption and output. ${ }^{9}$

As the gain parameter increases, the sophisticated learning rule can amplify the dynamic responses to a technology shock in the same magnitude as does the simple learning mechanism studied in Section V. Figure 5 displays such an example, where we set $g=0.05$ and $t_{0}=10000$. As one can see, the impulse responses under our alternative learning are qualitatively similar to those under the benchmark learning rule shown in Figure 1.

\footnotetext{
${ }^{8}$ With imperfectly rational agents, it seems logically incoherent to generate the initial data. Nonetheless, we follow this approach in the literature to make our work comparable.

${ }^{9}$ To conserve space, we do not present the impulse responses following the biased technology shock under the alternative learning rule. These results are similar to those displayed in Figure 2.
} 
It is important to note that the dynamics under nonlinear learning are in general sensitive not only to changes in initial conditions and the size of the gain, as found by Carceles-Poveda and Giannitsarou (2007), but also to changes in some of the deep parameters. ${ }^{10}$ Consider a case with a smaller sample of initial data $\left(t_{0}=100\right.$ instead of 10000) and with a smaller Frisch elasticity of labor supply ( $\eta=2$ instead of 0 ). Figure 6 shows the impulse responses to a positive neutral technology shock in this case. The results reveal that the learning model is capable of generating negative responses of labor hours following a neutral technology shock even in this one-sector growth model that abstracts from other frictions such as habit formation and investment adjustment costs considered by, for example, Francies and Ramey (2005). In response to the neutral technology shock, consumption rises more and output rises less in the learning model than in the rational-expectations model. The sharp rise in consumption shifts the labor supply curve up so much that the real wage rises sharply and the hours fall. In the mean time, the sharp rise in consumption and the modest rise in output leads to a smaller rise in investment than that in the rational expectations model.

The most interesting result is that hours can decline following a positive neutral technology shock in the learning model, whereas the responses of hours are always positive under rational expectations. Recent empirical work has documented evidence in favor of negative responses of hours to a positive neutral technology shock (e.g., Galí (1999) and Basu, Fernald, and Kimball (2006)). Learning, serving as a friction, is capable of generating the responses of investment and hours similar to Francies and Ramey (2005), where investment-adjustment costs and habit are introduced into a standard real-business-cycle model as alternative frictions.

In summary, the exercise in this section shows that the sophisticated learning rule has much flexibility to amplify the effects of technology shocks and produce qualitatively different transmission mechanisms than does the rational-expectations model. Since this learning mechanism is nonlinear, not only changes in initial conditions and the size of the gain can alter the equilibrium dynamics, changes in the size of shock variance can also affect the dynamics considerably. In future work, therefore,

\footnotetext{
${ }^{10}$ Our sophisticated learning rule is similar to the one studied by Carceles-Poveda and Giannitsarou (2007), who also examine the role of learning in a stochastic growth model. As in CarcelesPoveda and Giannitsarou (2007), we find that the dynamics are sensitive to changes in the initial conditions and the size of the gain. Different from Carceles-Poveda and Giannitsarou (2007), we focus on the model's ability to generate plausible labor market dynamics, whereas Carceles-Poveda and Giannitsarou (2007) assumes inelastically supplied labor.
} 
we would like to estimate the initial conditions, the variances, and the gain parameters along with other model parameters, as proposed in Sargent, Williams, and Zha (2006b).

\section{CONCLUSION}

We have studied a standard stochastic growth model with adaptive expectations in which beliefs are decoupled from decision rules. For the benchmark learning rule studied in Marcet and Nicolini (2003) and Sargent, Williams, and Zha (2006a), we have established that there exists a unique, stable SCE in our learning model and that the SCE is the same as the steady state REE. In contrast to the existing literature, however, we have shown that the learning model can generate substantially different dynamics from those implied by the rational expectations model. These differences are not driven by escape dynamics.

It is known that technology shocks in the standard growth model do not generate enough fluctuations in key macroeconomic variables such as hours and output. Introducing learning in the growth model dampens the wealth effect. This muted wealth effect, coupled with the strong intertemporal substitution effect, amplifies the responses of macroeconomic variables and can make dynamic responses hump-shaped. These results hold true with a more sophisticated learning rule under certain initial conditions.

Our results suggest that the learning mechanism is flexible enough to generate some realistic features in a simple one-sector growth model. Our findings also suggest that, to gauge the full potential of the learning mechanism in propagating the shocks in the growth model, one would need to jointly estimate the initial conditions with the gain parameter and other deep parameters. We hope our work helps motivate future empirical studies on the importance of learning. 


\section{Appendix A. Analytical Solution}

The coefficients in (29) in Proposition 1 are defined as:

$$
\begin{gathered}
\gamma_{1, \mathrm{com}}=\beta(1-\alpha)\left(c_{k}+1\right)\left[1+(1+\eta) c_{k}\right]+\eta\left(1-\alpha i_{k}\right)+(1-\alpha+\eta) \\
\gamma_{2, \mathrm{com}}=\left[\beta(1-\alpha)\left(c_{k}+1\right)-1\right]\left[(1+\eta) c_{k}+1\right]+(1+\eta)\left(1-\alpha i_{k}\right) \\
\gamma_{1}=\frac{\beta(1-\alpha)\left(c_{k}+1\right)+\eta}{\gamma_{1, \mathrm{com}}} \\
\gamma_{2}=\frac{(1-\alpha)(1+\eta) y_{k}+(1-\alpha+\eta)\left(1-i_{k}\right)}{\gamma_{1, \mathrm{com}}} \\
\gamma_{\nu 1}=\frac{\left(\rho_{\nu}-1\right) \gamma_{2, \mathrm{com}}+\alpha \eta y_{k}-(1-\alpha+\eta)\left(c_{k}+1\right)}{\gamma_{1, \mathrm{com}}} \\
\gamma_{\mu 1}=\frac{\left(\rho_{\mu}-1\right) \gamma_{2, \mathrm{com}}+\alpha \eta y_{k}-(1-\alpha+\eta)\left(c_{k}+1\right)}{\alpha \gamma_{1, \mathrm{com}}} \\
\gamma_{\nu 2}=\frac{(1-\alpha+\eta)\left(c_{k}+1\right)-\alpha \eta y_{k}}{\alpha \gamma_{1, \mathrm{com}}} \\
\gamma_{\mu 2}=\frac{(1-\alpha+\eta)\left(c_{k}+1\right)-\alpha \eta y_{k}}{}
\end{gathered}
$$

The steady state ratios such as $c_{k}$ and $i_{k}$ have been derived in Section III. One can verify that, for all admissible values of the deep parameters, that is, for any $\beta \in(0,1), \eta \geq 0, \alpha \in(0,1), \delta \in[0,1], \lambda_{z} \geq 1$, and $\lambda_{q} \geq 1$, all the steady-state ratios are well-defined and positive, and so are $\gamma_{1}$ and $\gamma_{2}$.

The closed-form solutions for investment, hours, output, and consumption are derived as the the following system of equations under either rational or adaptive expectations:

$$
\begin{gathered}
\hat{i}_{t}=k_{i} \hat{k}_{t}+\left(1-k_{i}\right) \hat{k}_{t-1}+\left(k_{i}-1\right) \Delta \hat{\nu}_{t}+\left(\frac{k_{i}-1}{\alpha}\right) \Delta \hat{\mu}_{t}, \\
\hat{l}_{t}=\frac{1}{\left[(1+\eta) c_{k}+\alpha i_{k}\right]} \hat{k}_{t}-\frac{\left[1-\alpha i_{k}\right]}{\left[(1+\eta) c_{k}+\alpha i_{k}\right]} \hat{k}_{t-1} \\
+\frac{\left(1-\alpha i_{k}\right)}{\left[(1+\eta) c_{k}+\alpha i_{k}\right]} \Delta \hat{\nu}_{t}+\frac{\left(\alpha^{-1}-i_{k}\right)}{\left[(1+\eta) c_{k}+\alpha i_{k}\right]} \Delta \hat{\mu}_{t}, \\
\hat{y}_{t}=\frac{\alpha}{\left[(1+\eta) c_{k}+\alpha i_{k}\right]} \hat{k}_{t}+\frac{\left[(1-\alpha)(1+\eta) c_{k}-\alpha\left(1-i_{k}\right)\right]}{\left[(1+\eta) c_{k}+\alpha i_{k}\right]} \hat{k}_{t-1} \\
+\frac{\alpha\left(1-i_{k}\right)-(1-\alpha)(1+\eta) c_{k}}{\left[(1+\eta) c_{k}+\alpha i_{k}\right]} \Delta \hat{\nu}_{t} \\
+\frac{\left(1-i_{k}\right)-\alpha-1(1-\alpha)(1+\eta) c_{k}}{\left[(1+\eta) c_{k}+\alpha i_{k}\right]},
\end{gathered}
$$




$$
\begin{gathered}
\hat{c}_{t}=\frac{\alpha-1-\eta}{\left[(1+\eta) c_{k}+\alpha i_{k}\right]} \hat{k}_{t}+\frac{\left[(1-\alpha)(1+\eta) y_{k}+(1+\eta-\alpha)\left(1-i_{k}\right)\right]}{\left[(1+\eta) c_{k}+\alpha i_{k}\right]} \hat{k}_{t-1} \\
+\frac{\alpha\left(1+\eta i_{k}\right)-(1+\eta)\left[1+(1-\alpha) c_{k}\right]}{\left[(1+\eta) c_{k}+\alpha i_{k}\right]} \Delta \hat{\nu}_{t} \\
+\frac{\left(1+\eta i_{k}\right)-\alpha^{-1}(1+\eta)\left[1+(1-\alpha) c_{k}\right]}{\left[(1+\eta) c_{k}+\alpha i_{k}\right]} \Delta \hat{\mu}_{t} .
\end{gathered}
$$

It is clear how the equilibrium can be solved. Once the solution for capital is obtained, as shown in Section IV, Equation (A1) can be used to solve for investment, (A2) for labor, (A3) for output, and (A4) for consumption.

\section{Appendix B. Proof of Proposition 1}

By successive substitutions in (23)-(27), one can derive (29). Specific steps are described below.

We begin by first deriving the following two relations from (25) and (26):

$$
\begin{aligned}
& \hat{y}_{t}=\hat{i}_{t}-(1+\eta) c_{i} \hat{l}_{t}, \\
& \hat{c}_{t}=\hat{i}_{t}-(1+\eta) y_{i} \hat{l}_{t} .
\end{aligned}
$$

Substituting (A5) into (23), we get:

$$
\hat{i}_{t}=\left[(1+\eta) c_{i}+\alpha\right] \hat{l}_{t}+(1-\alpha) \hat{k}_{t-1}-(1-\alpha) \Delta \hat{\nu}_{t}-\left(\frac{1-\alpha}{\alpha}\right) \Delta \hat{\mu}_{t} .
$$

Substituting (A7) into (24) yields

$$
\hat{k}_{t}=\left[(1+\eta) c_{k}+\alpha i_{k}\right] \hat{l}_{t}+\left(1-\alpha i_{k}\right) \hat{k}_{t-1}-\left(1-\alpha i_{k}\right) \Delta \hat{\nu}_{t}-\left(\frac{1-\alpha i_{k}}{\alpha}\right) \Delta \hat{\mu}_{t} .
$$

Substituting (A6) and (A7) into (27) yields

$$
\begin{aligned}
{\left[1-\frac{\alpha \beta(1-\delta)}{\lambda_{z} \lambda_{q}^{1 / \alpha}}+\eta\right] } & E_{t} \hat{l}_{t+1}-\left[1-\frac{\alpha \beta(1-\delta)}{\lambda_{z} \lambda_{q}^{1 / \alpha}}\right] \hat{k}_{t} \\
& =(1-\alpha+\eta) \hat{l}_{t}-(1-\alpha) \hat{k}_{t-1} \\
& +(1-\alpha) \Delta \hat{\nu}_{t}+\frac{\alpha \beta(1-\delta)}{\lambda_{z} \lambda_{q}^{1 / \alpha}} E_{t} \Delta \hat{\nu}_{t+1} \\
& +\frac{1-\alpha}{\alpha} \Delta \hat{\mu}_{t}+\frac{\beta(1-\delta)}{\lambda_{z} \lambda_{q}^{1 / \alpha}} E_{t} \Delta \hat{\mu}_{t+1} .
\end{aligned}
$$


Rewrite (A8) as

$$
\begin{gathered}
\hat{l}_{t}=\frac{1}{(1+\eta) c_{k}+\alpha i_{k}} \hat{k}_{t} \\
-\frac{1-\alpha i_{k}}{(1+\eta) c_{k}+\alpha i_{k}} \hat{k}_{t-1} \\
+\frac{1-\alpha i_{k}}{(1+\eta) c_{k}+\alpha i_{k}} \Delta \hat{\nu}_{t} \\
+\frac{\left\{1-\alpha i_{k}\right\}\left(\frac{1}{\alpha}\right)}{(1+\eta) c_{k}+\alpha i_{k}} \Delta \hat{\mu}_{t} .
\end{gathered}
$$

It follows that

$$
\begin{aligned}
& {\left[1-\frac{\alpha \beta(1-\delta)}{\lambda_{z} \lambda_{q}^{1 / \alpha}}+\eta\right] E_{t} \hat{l}_{t+1}=\frac{\left[1-\frac{\alpha \beta(1-\delta)}{\lambda_{z} \lambda_{q}^{1 / \alpha}}+\eta\right]}{\left(1-\frac{1-\delta}{\lambda_{z} \lambda_{q}^{1 / \alpha}}\right)\left(\frac{1-c_{y}}{i_{y}}\right)\left[\frac{c_{y}(1+\eta)}{1-c_{y}}+\alpha\right]} E_{t} \hat{k}_{t+1}} \\
& -\frac{\left[1-\frac{\alpha \beta(1-\delta)}{\lambda_{z} \lambda_{q}^{1 / \alpha}}+\eta\right]\left\{1-\alpha i_{k}\right\}}{\left(1-\frac{1-\delta}{\lambda_{z} \lambda_{q}^{1 / \alpha}}\right)\left(\frac{1-c_{y}}{i_{y}}\right)\left[\frac{c_{y}(1+\eta)}{1-c_{y}}+\alpha\right]} \hat{k}_{t} \\
& +\frac{\left[1-\frac{\alpha \beta(1-\delta)}{\lambda_{z} \lambda_{q}^{1 / \alpha}}+\eta\right]\left\{\left(1-\frac{1-\delta}{\lambda_{z} \lambda_{q}^{1 / \alpha}}\right)\left[\frac{\left(1-c_{y}\right)(1-\alpha)}{i_{y}}\right]+\frac{1-\delta}{\lambda_{z} \lambda_{q}^{1 / \alpha}}\right\}}{\left(1-\frac{1-\delta}{\lambda_{z} \lambda_{q}^{1 / \alpha}}\right)\left(\frac{1-c_{y}}{i_{y}}\right)\left[\frac{c_{y}(1+\eta)}{1-c_{y}}+\alpha\right]} E_{t} \Delta \hat{\nu}_{t+1} \\
& +\frac{\left[1-\frac{\alpha \beta(1-\delta)}{\lambda_{z} \lambda_{q}^{1 / \alpha}}+\eta\right]\left\{\left(1-\frac{1-\delta}{\lambda_{z} \lambda_{q}^{1 / \alpha}}\right)\left[\frac{\left(1-c_{y}\right)(1-\alpha)}{i_{y}}\right]+\frac{1-\delta}{\lambda_{z} \lambda_{q}^{1 / \alpha}}\right\}\left(\frac{1}{\alpha}\right)}{\left(1-\frac{1-\delta}{\lambda_{z} \lambda_{q}^{1 / \alpha}}\right)\left(\frac{1-c_{y}}{i_{y}}\right)\left[\frac{c_{y}(1+\eta)}{1-c_{y}}+\alpha\right]} E_{t} \Delta \hat{\mu}_{t+1} .
\end{aligned}
$$

Substituting (A10) and (A11) into (A9), and rearranging, we get

$$
\begin{aligned}
\chi_{k, 1} E_{t} \hat{k}_{t+1}+\chi_{k, 0} \hat{k}_{t}+\chi_{k,-1} \hat{k}_{t-1}+\chi_{\nu, 1} E_{t} \Delta \hat{\nu}_{t+1} \\
+\chi_{\nu, 0} \Delta \hat{\nu}_{t}+\chi_{\mu, 1} E_{t} \Delta \hat{\mu}_{t+1}+\chi_{\mu, 0} \Delta \hat{\mu}_{t}=0
\end{aligned}
$$

where

$$
\begin{gathered}
\chi_{k, 1}=\frac{\left[1-\frac{\alpha \beta(1-\delta)}{\lambda_{z} \lambda_{q}^{1 / \alpha}}+\eta\right]}{\left(1-\frac{1-\delta}{\lambda_{z} \lambda_{q}^{1 / \alpha}}\right)\left(\frac{1-c_{y}}{i_{y}}\right)\left[\frac{c_{y}(1+\eta)}{1-c_{y}}+\alpha\right]} \\
\chi_{k, 0}=-\frac{\left[1-\frac{\alpha \beta(1-\delta)}{\lambda_{z} \lambda_{q}^{1 / \alpha}}+\eta\right]\left\{1-\alpha i_{k}\right\}+(1-\alpha+\eta)}{\left(1-\frac{1-\delta}{\lambda_{z} \lambda_{q}^{1 / \alpha}}\right)\left(\frac{1-c_{y}}{i_{y}}\right)\left[\frac{c_{y}(1+\eta)}{1-c_{y}}+\alpha\right]}-\left[1-\frac{\alpha \beta(1-\delta)]}{\left.\lambda_{z} \lambda_{q}^{1 / \alpha}\right]}+(1-\alpha)\right. \\
\chi_{k,-1}=\frac{(1-\alpha+\eta)\left\{1-\alpha i_{k}\right\}}{\left(1-\frac{1-\delta}{\lambda_{z} \lambda_{q}^{1 / \alpha}}\right)\left(\frac{1-c_{y}}{i_{y}}\right)\left[\frac{c_{y}(1+\eta)}{1-c_{y}}+\alpha\right]}+
\end{gathered}
$$




$$
\begin{aligned}
& \chi_{\nu, 1}=\frac{\left[1-\frac{\alpha \beta(1-\delta)}{\lambda_{z} \lambda_{q}^{1 / \alpha}}+\eta\right]\left\{\left(1-\frac{1-\delta}{\lambda_{z} \lambda_{q}^{1 / \alpha}}\right)\left[\frac{\left(1-c_{y}\right)(1-\alpha)}{i_{y}}\right]+\frac{1-\delta}{\lambda_{z} \lambda_{q}^{1 / \alpha}}\right\}}{\left(1-\frac{1-\delta}{\lambda_{z} \lambda_{q}^{1 / \alpha}}\right)\left(\frac{1-c_{y}}{i_{y}}\right)\left[\frac{c_{y}(1+\eta)}{1-c_{y}}+\alpha\right]}-\frac{\alpha \beta(1-\delta)}{\lambda_{z} \lambda_{q}^{1 / \alpha}} \\
& \chi_{\nu, 0}=-\frac{(1-\alpha+\eta)\left\{\left(1-\frac{1-\delta}{\lambda_{z} \lambda_{q}^{1 / \alpha}}\right)\left[\frac{\left(1-c_{y}\right)(1-\alpha)}{i_{y}}\right]+\frac{1-\delta}{\lambda_{z} \lambda_{q}^{1 / \alpha}}\right\}}{\left(1-\frac{1-\delta}{\lambda_{z} \lambda_{q}^{1 / \alpha}}\right)\left(\frac{1-c_{y}}{i_{y}}\right)\left[\frac{c_{y}(1+\eta)}{1-c_{y}}+\alpha\right]}-(1-\alpha) \\
& \chi_{\mu, 1}=\frac{\left[1-\frac{\alpha \beta(1-\delta)}{\lambda_{z} \lambda_{q}^{1 / \alpha}}+\eta\right]\left\{\left(1-\frac{1-\delta}{\lambda_{z} \lambda_{q}^{1 / \alpha}}\right)\left[\frac{\left(1-c_{y}\right)(1-\alpha)}{i_{y}}\right]+\frac{1-\delta}{\lambda_{z} \lambda_{q}^{1 / \alpha}}\right\}\left(\frac{1}{\alpha}\right)}{\left(1-\frac{1-\delta}{\lambda_{z} \lambda_{q}^{1 / \alpha}}\right)\left(\frac{1-c_{y}}{i_{y}}\right)\left[\frac{c_{y}(1+\eta)}{1-c_{y}}+\alpha\right]}-\frac{\beta(1-\delta)}{\lambda_{z} \lambda_{q}^{1 / \alpha}} \\
& \chi_{\mu, 0}=-\frac{(1-\alpha+\eta)\left\{\left(1-\frac{1-\delta}{\lambda_{z} \lambda_{q}^{1 / \alpha}}\right)\left[\frac{\left(1-c_{y}\right)(1-\alpha)}{i_{y}}\right]+\frac{1-\delta}{\lambda_{z} \lambda_{q}^{1 / \alpha}}\right\}\left(\frac{1}{\alpha}\right)}{\left(1-\frac{1-\delta}{\lambda_{z} \lambda_{q}^{1 / \alpha}}\right)\left(\frac{1-c_{y}}{i_{y}}\right)\left[\frac{c_{y}(1+\eta)}{1-c_{y}}+\alpha\right]}-\frac{1-\alpha}{\alpha} .
\end{aligned}
$$

Further simplifying, we get

$$
\hat{k}_{t}=\gamma_{1} E_{t} \hat{k}_{t+1}+\gamma_{2} \hat{k}_{t-1}+\chi_{\nu, 1}^{k} E_{t} \Delta \hat{\nu}_{t+1}+\chi_{\nu, 0}^{k} \Delta \hat{\nu}_{t}+\chi_{\mu, 1}^{k} E_{t} \Delta \hat{\mu}_{t+1}+\chi_{\mu, 0}^{k} \Delta \hat{\mu}_{t},
$$

where

$$
\begin{gathered}
\gamma_{1}=\frac{\beta(1-\alpha)\left(c_{k}+1\right)+\eta}{\beta(1-\alpha)\left(c_{k}+1\right)\left[1+(1+\eta) c_{k}\right]+\eta\left(1-\alpha i_{k}\right)+(1-\alpha+\eta)} \\
\gamma_{2}=\frac{(1-\alpha)(1+\eta) y_{k}+(1-\alpha+\eta)\left(1-i_{k}\right)}{\beta(1-\alpha)\left(c_{k}+1\right)\left[1+(1+\eta) c_{k}\right]+\eta\left(1-\alpha i_{k}\right)+(1-\alpha+\eta)} \\
\chi_{\nu, 1}^{k}=\frac{\left[\beta(1-\alpha)\left(c_{k}+1\right)-1\right]\left[(1+\eta) c_{k}+1\right]+(1+\eta)\left(1-\alpha i_{k}\right)}{\beta(1-\alpha)\left(c_{k}+1\right)\left[1+(1+\eta) c_{k}\right]+\eta\left(1-\alpha i_{k}\right)+(1-\alpha+\eta)} \\
\chi_{\nu, 0}^{k}=-\frac{(1-\alpha+\eta)\left(c_{k}+1\right)-\alpha \eta y_{k}}{\beta(1-\alpha)\left(c_{k}+1\right)\left[1+(1+\eta) c_{k}\right]+\eta\left(1-\alpha i_{k}\right)+(1-\alpha+\eta)} \\
\chi_{\mu, 1}^{k}=\frac{\left[\beta(1-\alpha)\left(c_{k}+1\right)-1\right]\left[(1+\eta) c_{k}+1\right]+(1+\eta)\left(1-\alpha i_{k}\right)}{\beta(1-\alpha)\left(c_{k}+1\right)\left[1+(1+\eta) c_{k}\right]+\eta\left(1-\alpha i_{k}\right)+(1-\alpha+\eta)}\left(\frac{1}{\alpha}\right) \\
\chi_{\mu, 0}^{k}=-\frac{(1-\alpha+\eta)\left(c_{k}+1\right)-\alpha \eta y_{k}}{\beta(1-\alpha)\left(c_{k}+1\right)\left[1+(1+\eta) c_{k}\right]+\eta\left(1-\alpha i_{k}\right)+(1-\alpha+\eta)}\left(\frac{1}{\alpha}\right) .
\end{gathered}
$$

Simplifying further, we have

$$
\begin{aligned}
\hat{k}_{t}=\gamma_{1} E_{t} \hat{k}_{t+1}+\gamma_{2} \hat{k}_{t-1}-\chi_{\nu, 0}^{k} \hat{\nu}_{t-1}+\left[\left(\rho_{\nu}-1\right) \chi_{\nu, 1}^{k}+\chi_{\nu, 0}^{k}\right] \hat{\nu}_{t} & \\
& -\chi_{\mu, 0}^{k} \hat{\mu}_{t-1}+\left[\left(\rho_{\mu}-1\right) \chi_{\mu, 1}^{k}+\chi_{\mu, 0}^{k}\right] \hat{\mu}_{t},
\end{aligned}
$$

which gives the results in Appendix A. 


\section{Appendix C. Proof of Proposition 2}

Because (29) is a second-order differential equation, there are only two solutions. We will show, next, that one solution is stationary and the other explosive. Thus, there is a unique stationary solution.

The coefficient $a$ in (30) takes on one of the following two values:

$$
a_{1}=\frac{1-\sqrt{1-4 \gamma_{1} \gamma_{2}}}{2 \gamma_{1}}, \quad a_{2}=\frac{1+\sqrt{1-4 \gamma_{1} \gamma_{2}}}{2 \gamma_{1}} .
$$

We can verify that $\gamma_{1}>0$ and $\gamma_{2}>0$ for all admissible values of the deep parameters. We can further show that $\gamma_{1}+\gamma_{2}<1$ if and only if $\beta(1-\delta)<\lambda_{z} \lambda_{q}^{1 / \alpha}$, which holds too for all admissible values of the deep parameters.

Since $\gamma_{1}>0, \gamma_{2}>0, \gamma_{1}+\gamma_{2}<1$, we have $\gamma_{1} \in(0,1), \gamma_{2} \in(0,1)$, and $4 \gamma_{1} \gamma_{2}<1$. It follows that $a_{1}$ and $a_{2}$ are real numbers. Knowing the above ranges for $\gamma_{1}$ and $\gamma_{2}$, we can in fact show that $a_{1} \in(0,1)$ and $a_{2}>1$. We can then verify that $\left(\rho_{\nu}+a_{1}\right) \gamma_{1}<1$ and $\left(\rho_{\mu}+a_{1}\right) \gamma_{1}<1$, which imply that $\gamma_{1} a_{1}<1$, and so the solution prescribed by $a=a_{1}$ above corresponds to a (unique) stationary rational expectations equilibrium. ${ }^{11}$ Given the initial condition $\hat{k}_{-1}$ and the driving processes, (30) completely pins down capital, and then (A1), (A2), (A3), and (A4) determine investment, labor, output, and consumption, respectively. From now on, whenever we mention REE, we refer to this stationary REE, where we also write $a_{1}$ simply as $a$.

\footnotetext{
${ }^{11}$ We can also show that, provided $\rho_{\nu} \neq a_{1}$ and $\rho_{\mu} \neq a_{1}$, the solution prescribed by $a=a_{2}$ above corresponds to an explosive path.
} 
TABLE 1. Benchmark parameter values

\begin{tabular}{llll}
\hline \hline Preference & $\beta=0.99$ & $\eta=0$ & $\xi=3.17$ \\
Labor share & $\alpha=0.7$ & & \\
Capital Depreciation & $\delta=0.03$ & & \\
Neutral Technology & $\lambda_{z}=1.0016$ & $\rho_{\nu}=0.95$ & $\sigma_{\nu}=0.01$ \\
Biased Technology & $\lambda_{q}=1.008$ & $\rho_{\mu}=0.95$ & $\sigma_{\mu}=0.005$ \\
Learning Gain & $g=0.05$ & & \\
\hline
\end{tabular}

TABLE 2. Cumulative responses of labor market varialbes relative to output following the neutral technology shock: benchmark parameters

\begin{tabular}{lllll}
\hline \hline & \multicolumn{2}{l}{ Rational expectations } & \multicolumn{2}{l}{ Adaptive expectations } \\
\hline Forecast Horizon & Hours & Real wage & Hours & Real wage \\
1 quarter & 0.67 & 0.33 & 1.05 & 0.05 \\
4 quarters & 0.58 & 0.42 & 0.71 & 0.36 \\
8 quarters & 0.49 & 0.51 & 0.58 & 0.61 \\
16 quarters & 0.35 & 0.65 & 0.53 & 0.83 \\
24 quarters & 0.30 & 0.74 & 0.52 & 0.93 \\
\hline
\end{tabular}


Responses to a Neutral Technology Shock: RE vs. Learning
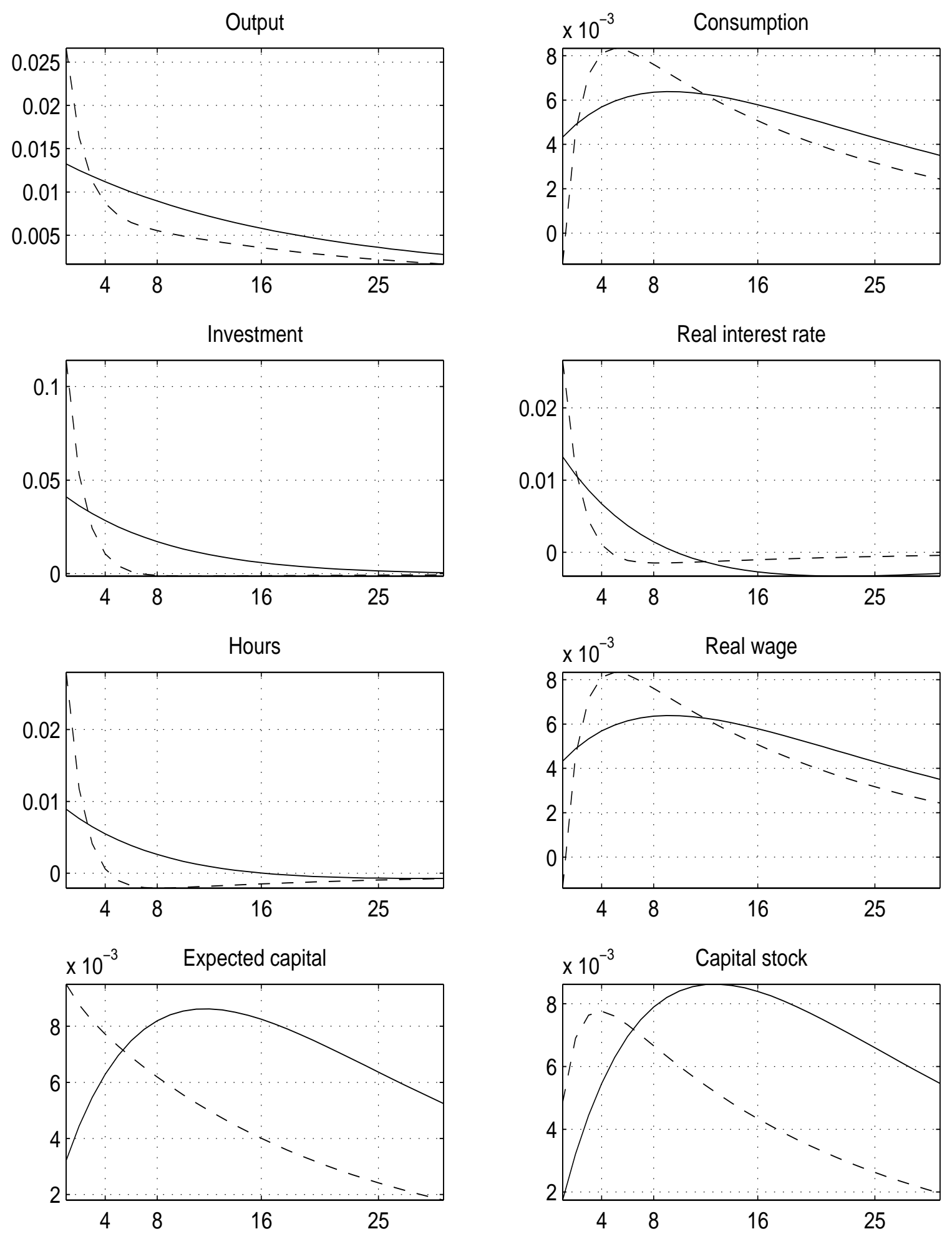

FiguRE 1. Benchmark model: Impulse responses to a one-standard deviation neutral technology shock. The solid line represents the responses under rational expectations. The dashed line represents the responses under adaptive expectations. 
Responses to a Biased Technology Shock: RE vs. Learning
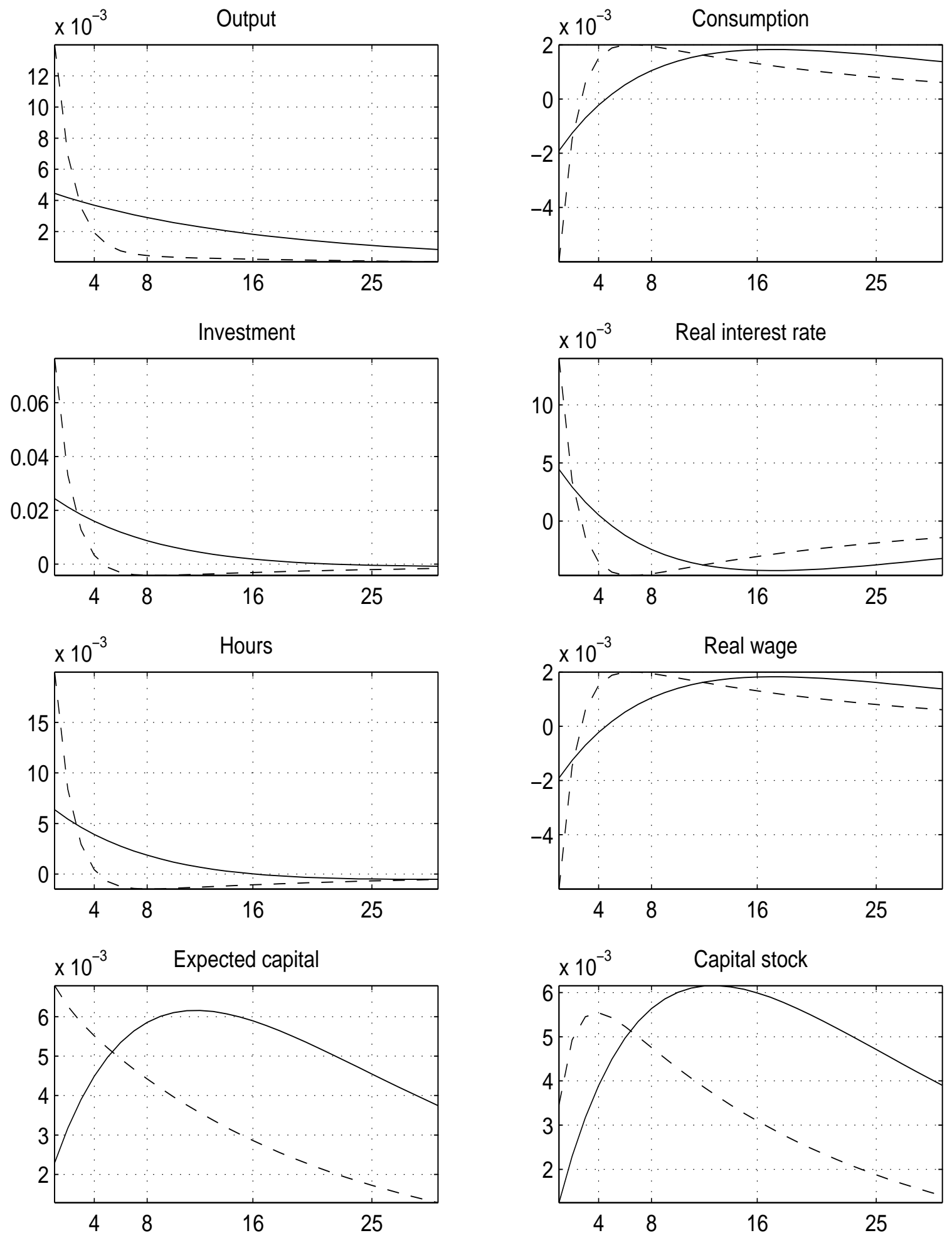

Figure 2. Benchmark model: Impulse responses to a one-standard deviation biased technology shock. The solid line represents the responses under rational expectations. The dashed line represents the responses under adaptive expectations. 


\section{Responses to a Neutral Technology Shock: RE vs. Learning}
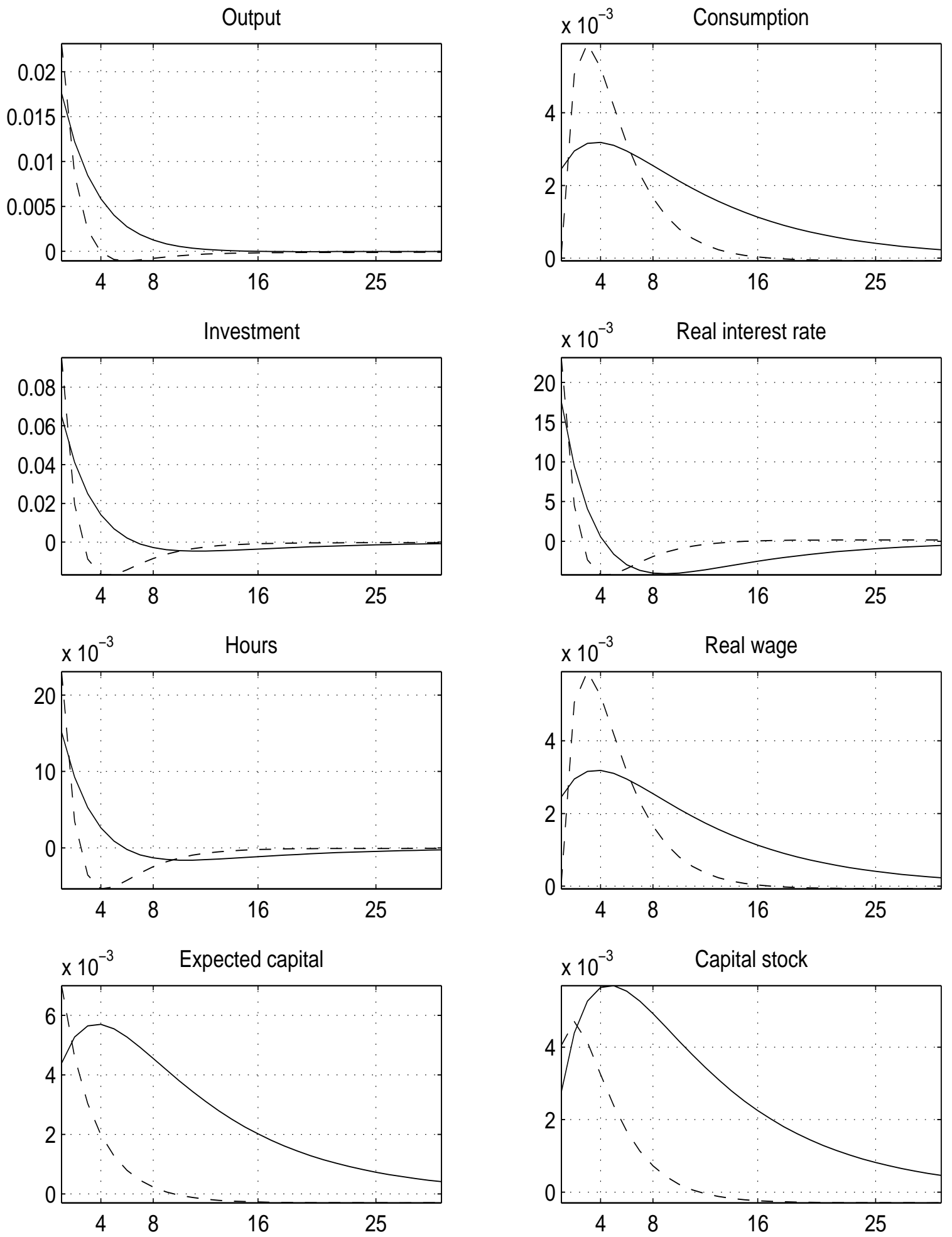

Figure 3. Benchmark model with low persistence of the shock: Impulse responses to a neutral technology shock. The solid line represents the responses under rational expectations. The dashed line represents the responses under adaptive expectations. 
Responses to a Neutral Technology Shock: RE vs. Learning
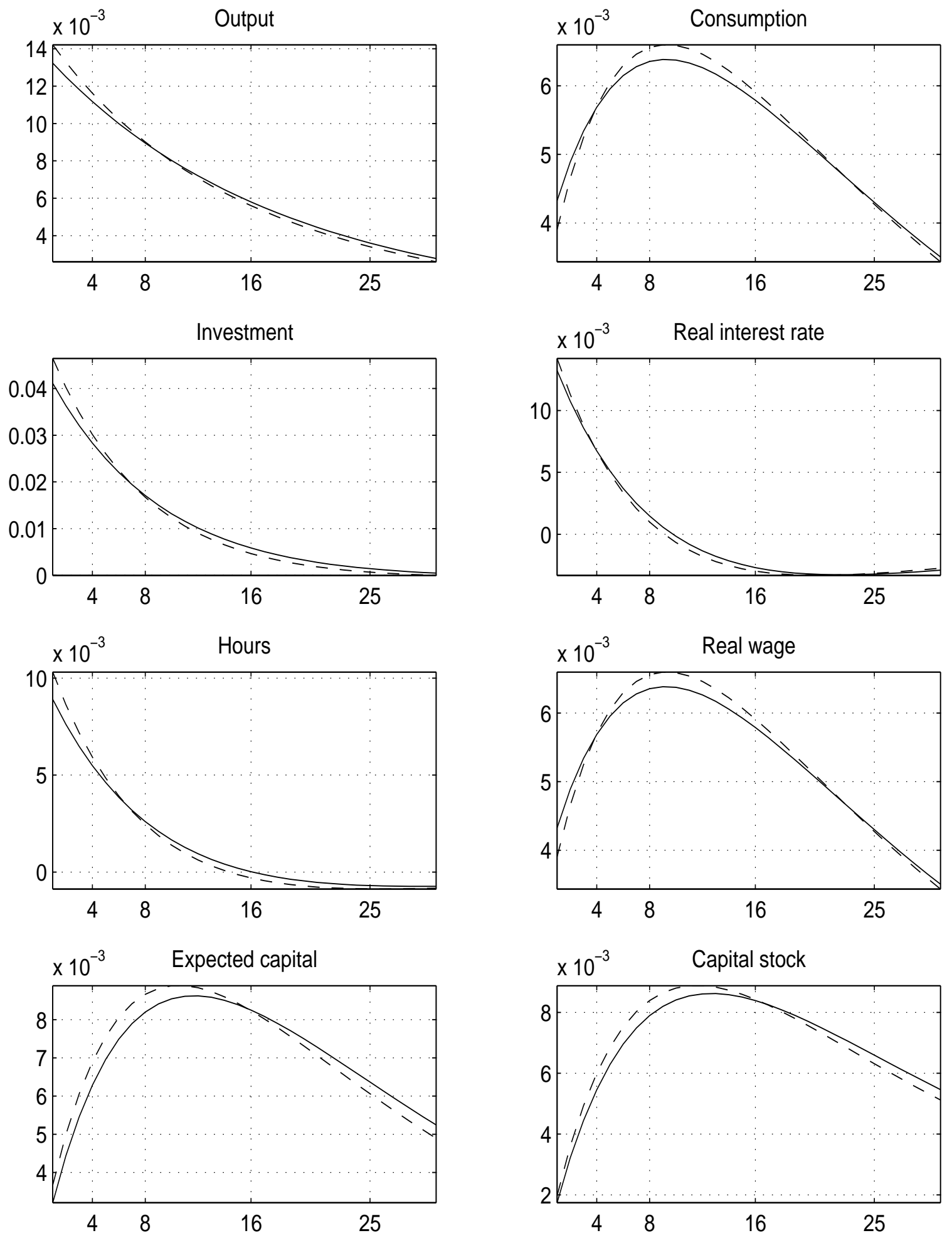

FigurE 4. Model with alternative learning rule $\left(g=0.001\right.$ and $t_{0}=$ 10000): Impulse responses to a neutral technology shock. The solid line represents the responses under rational expectations. The dashed line represents the responses under adaptive expectations. 


\section{Responses to a Neutral Technology Shock: RE vs. Learning}
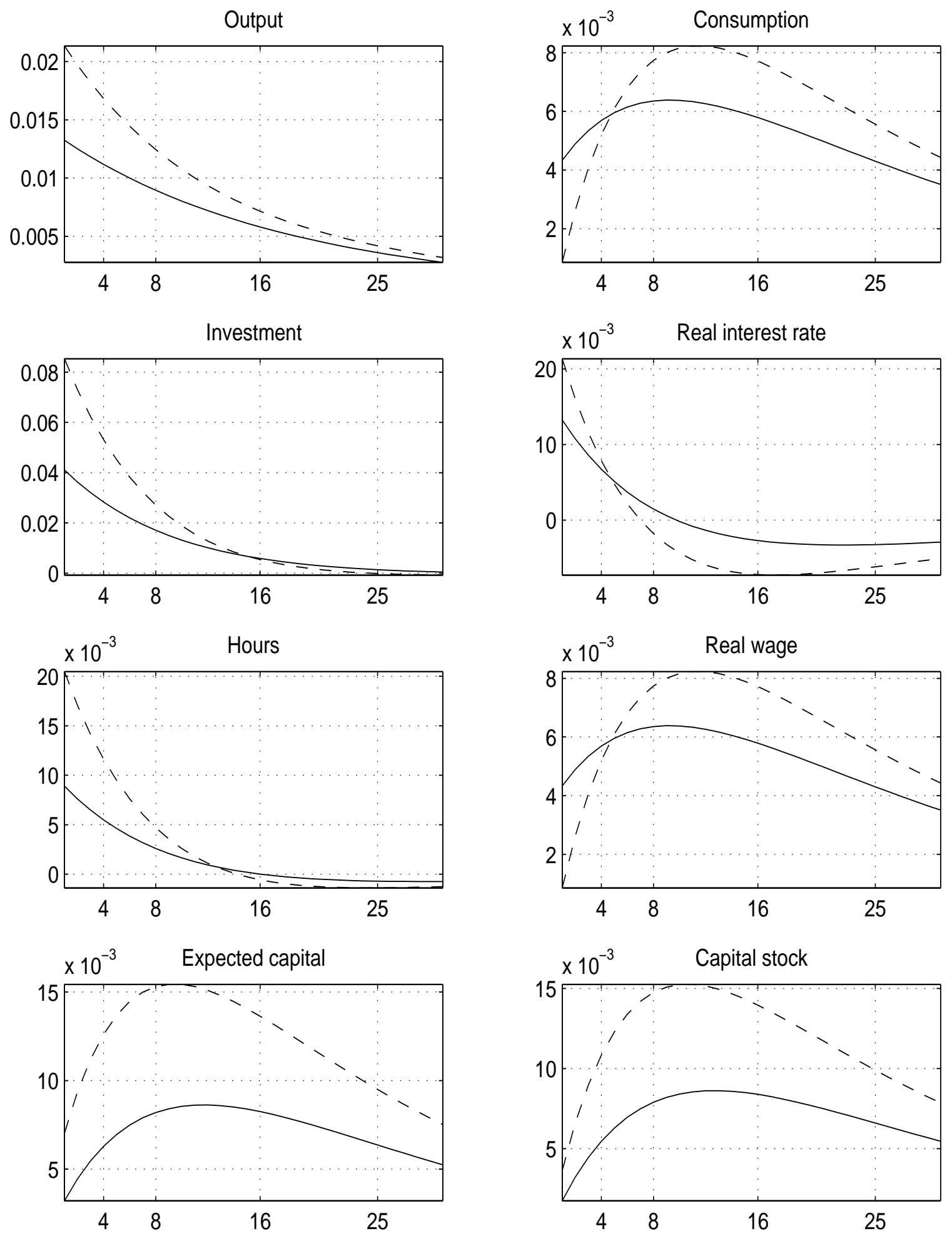

Figure 5. Model with alternative learning rule $\left(g=0.05\right.$ and $t_{0}=$ 10000): Impulse responses to a neutral technology shock. The solid line represents the responses under rational expectations. The dashed line represents the responses under adaptive expectations. 


\section{Responses to a Neutral Technology Shock: RE vs. Learning}
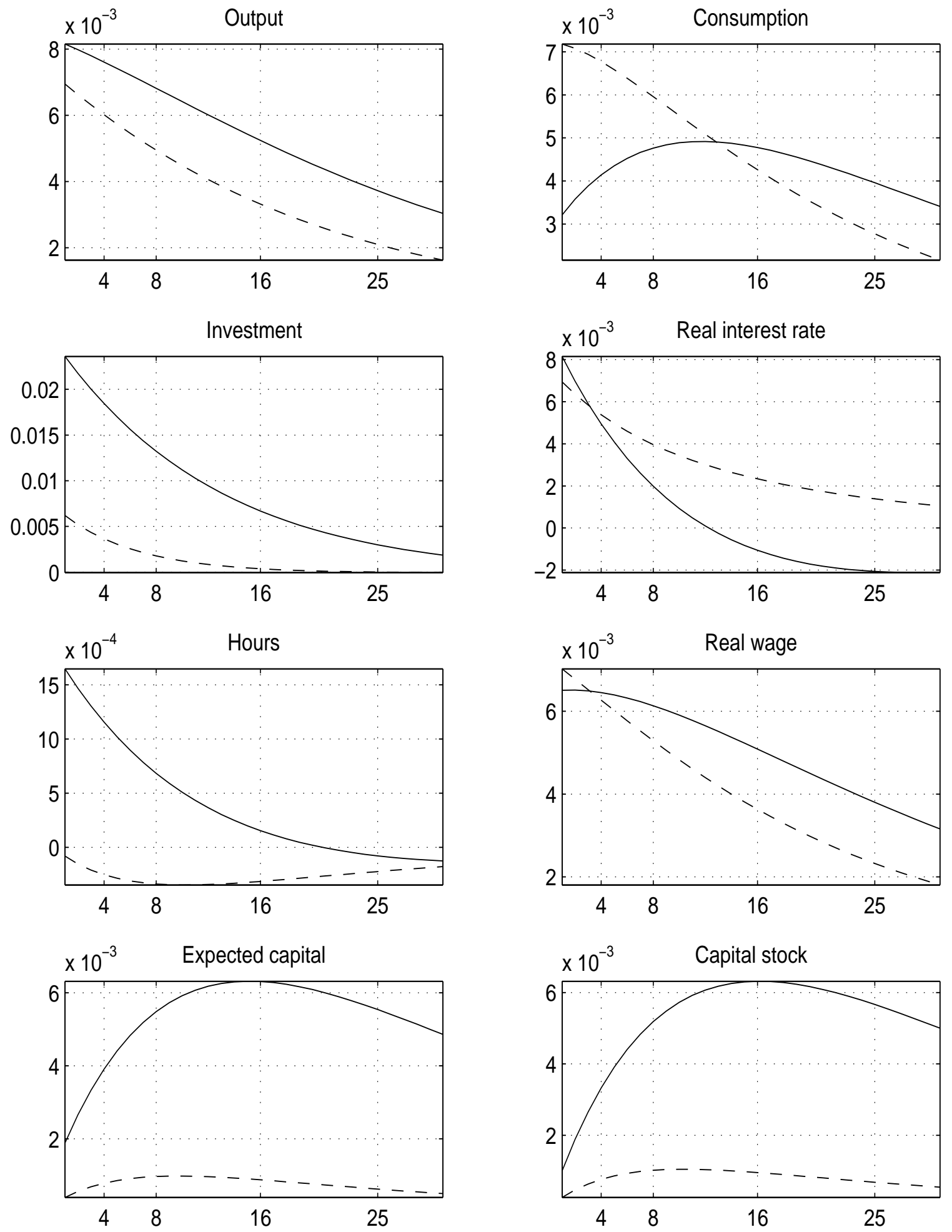

Figure 6. Model with alternative learning rule $\left(g=0.05\right.$ and $t_{0}=$ 100) and low Frisch elasticity $(\eta=2)$ : Impulse responses to a neutral technology shock. The solid line represents the responses under rational expectations. The dashed line represents the responses under adaptive expectations. 


\section{REFERENCES}

Adam, K., G. W. Evans, and S. Honkapohja (in press): "Are Hyperinflation Paths Learnable?," Journal of Economic Dynamics and Control.

Adam, K., A. Marcet, And J. P. Nicolini (2008): "Stock Market Volatility and Learning," Unpublished Manuscript, Universitat Pompeu Fabra.

Altig, D., L. J. Christiano, M. Eichenbaum, and J. Linde (2004): "FirmSpecific Capital, Nominal Rigidities and the Business Cycle," Federal Reserve Bank of Cleveland Working Paper 04-16.

Barro, R. J., And R. G. King (1984): "Time-Separable Preferences and Intertemporal Substitution Models of Business Cycles,", The Quarterly Journal of Economics, 99, 817-839.

Basu, S., J. G. Fernald, and M. S. Kimball (2006): "Are Technology Improvements Contractionary?," American Economic Review, 96(5), 1418-1448.

Bullard, J., And J. Duffy (2004): "Learning and Structural Change in Macroeconomic Data," Working Paper 2004-016, Federal Reserve Bank of St Louis.

Carboni, G., And M. Ellison (2008): "The Great Inflation and the Greenbook," Manuscript, European Central Bank and University of Oxford.

Carceles-Poveda, E., and C. Giannitsarou (2007): "Adaptive Learning in Practice," Journal of Economic Dynamics \& Contral, 31, 2659-2697.

Cho, I.-K., N. Williams, and T. J. Sargent (2002): "Escaping Nash Inflation," Review of Economic Studies, 69, 1-40.

Christiano, L., And M. Eichenbaum (1992): "Current Real Business Cycle Theories and Aggregate Labor Market Fluctuations," American Economic Review, 82(3), 430-450.

Edge, R., T. Laubach, and J. Williams (2007): "Learning and Shifts in LongRun Productivity Growth," Journal of Monetary Economics, pp. 2421-2438.

Eusepi, S., And B. Preston (2008): "Expectations, Learning and Business Cycle Fluctuations," Working Paper, Federal Reserve Bank of New York and Columbia University.

Evans, G., and S. Honkapohja (2001): Learning and Expectations in Macroeconomics. Princeton University Press, Princeton, New Jersey.

Fisher, J. D. (2006): "The Dynamic Effects of Neutral and Investment-Specific Technology Shocks," Journal of Political Economy, 114, 413-452.

Francies, N., and V. A. RAmey (2005): "Is the technology-driven real business cycle hypothesis dead? Shocks and aggregate fluctuations revisited," Journal of Monetary Economics, 52(8), 1379-1399. 
Galí, J. (1999): "Technology, employment, and the business cycle: Do technology shocks explain aggregate fluctuations?," American Economic Review, 89(1), 249271.

Gambetti, L. (2006): "Technology Shocks and the Response of Hours Worked: Time-Varying Dynamics Matter," Ph.D. thesis, University of Pompeu Fabra.

Greenwood, J., Z. Hercowitz, and P. Krusell (1997): "Long-Run Implications of Investment-Specific Technological Change," American Economic Review, $87,342-362$.

- (2000): "The Role of Investment-Specific Technological Change in the Business Cycle," European Economic Review, 44, 91-115.

Hansen, G. D. (1985): "Indivisible Labor and the Business Cycle," Journal of Monetary Economics, 16, 309-337.

He, H., And Z. LiU (2008): "Investment-Specific Technological Change, Skill Accumulation, and Wage Inequality," Review of Economic Dynamics, 11, 314-334.

Jaimovich, N., And S. Rebelo (2008): "Can News About the Future Drive the Business Cycle?," Manuscript, Standford University and Northwestern University.

KasA, K. (2004): "Learning, Large Deviations, And Recurrent Currency Crises," International Economic Review, 45, 141-173.

Krusell, P., L. E. Ohanian, J. V. Ríos-Rull, and G. L. Violante (2000): "Capital-Skill Complementarity and Inequality: A Macroeconomic Analysis," Econometrica, 68(5), 1029-1053.

Kushner, H. J., And G. G. YIn (1997): Stochastic Approximation Algorithms and Applications. Springer-Verlag.

Lettau, M., and H. Uhlig (2000): "Can Habit Formation Be Reconciled with Business Cycle Facts?," Review of Economic Dynamics, 3, 79-99.

Liu, Z., D. F. Waggoner, And T. Zha (2008): "Has the Federal Reserve's Inflation Target Changed?," Manuscript,Emory University and the Federal Reserve Bank of Atlanta.

LUCAS, JR., R. E. (1986): "Adaptive Behavior and Economic Theory," Journal of Business, 59, S401-S426.

Marcet, A., And J. P. Nicolini (2003): "Recurrent Hyperinflations and Learning," American Economic Review, 93(5), 1476-1498.

Marcet, A., And T. J. SArgent (1989): "Convergence of Least Squares Learning Mechanisms in Self-Referential Linear Stochastic Models," Journal of Economic Theory, 48, 337-368. 
Primiceri, G. (2006): "Why Inflation Rose and Fell: Policy-Makers' Beliefs and U. S. Postwar Stabilization Policy," Quarterly Journal of Economics, 121(3), 867-901. Rogerson, R. (1988): "Indivisible Labor, Lotteries and Equilibrium," Journal of Monetary Economics, 21, 3-16.

Sargent, T. J. (1999): The Conquest of American Inflation. Princeton University Press, Princeton, New Jersey.

— (2007): "Evolution and Intelligent Design," AEA Presidential Address, New York University.

Sargent, T. J., and N. Williams (2005): "Impacts of Priors on Convergence and Escapes from Nash Inflation," Review of Economic Dynamics, 8(2), 360-391.

Sargent, T. J., N. Williams, and T. Zha (2006a): "The Conquest of South American Inflation," NBER Working Paper No. 12606.

- (2006b): "Shocks and Government Beliefs: The Rise and Fall of American Inflation," American Economic Review, 96(4), 1193-1224.

Williams, N. (2003): "Adaptive Learning and Business Cycles," Manuscript, Princeton University.

Vanderbilt University, Federal Reserve Bank of San Francisco and Emory University, Federal Reserve Bank of Atlanta and Emory University 